\title{
Evidence of movement variability patterns during a repetitive pointing task until exhaustion
}

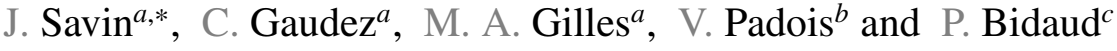 \\ ${ }^{a}$ INRS Vandoeuvre-lès-Nancy, F-54500, France \\ ${ }^{b}$ Auctus - INRIA-IMS CNRS UMR 5218 Université de Bordeaux, Talence, F-33400, France \\ ${ }^{c}$ ONERA Palaiseau, F-91120, France
}

\section{ARTICLE INFO}

\section{Keywords:}

Movement variability

Muscle fatigue

Repetitive pointing task

Ergonomic assessment

Principal components analysis

Hierarchical ascending classification

\begin{abstract}
A B S T R A C T
Human movement is characterized by its variability: the same task is never performed twice in exactly the same way. This variability is believed to play a functional role in movement performance and adaptability, as well as in preventing musculoskeletal damage. This article focuses on the time-evolution of movement variability throughout a repetitive pointing task until exhaustion. The kinematics of 13 subjects performing the pointing task is analyzed. Principal Component Analysis of joint angles identifies joint coordinations for each pointing cycle, and cycle-by-cycle comparison highlights movement variability. Non-supervised clustering reveals that subjects adopt successive coordination patterns at an intra-individual level. Inter-individual variability is characterized by the number and type of such patterns: from 3 to 5 patterns, mobilizing the trunk, the shoulder and the upper limbs differently. Movement variability exists even in a seemingly basic and constrained task. It appears in the very early stages of fatigue onset, and may correspond to adaptative coordination responses throughout task performance. This observation should encourage workstation designers to better account for movement variability in order to preserve operators' health and safety.
\end{abstract}

\section{Introduction}

Movement variability (MV) is a primary feature of human motion: whether considering one person at different times, or several different people, a prescribed movement is never performed exactly the same way twice [1-5]. This also applies to movements at the workstation, which should have implications on the way such work equipment is designed.

Motor control theories state that MV is related to the redundancy, or rather to the abundancy, of the locomotor system and its control: the number of degrees of freedom (DOF) required to perform a manual task is generally lower than the number of DOF in the human body, the latter being itself far lower than the number of its actuating units, namely muscles. This abundancy (in kinematics and actuation) theoretically offers a large number of ways to perform a prescribed task [6]. The literature demonstrates a growing interest in this topic [7-9].

At the workstation, MV can be influenced by factors related to the prescribed task (pace, weight of the tools used, the geometry and dimensions of the workstation, the nature of the task, etc.). It may also be influenced by factors intrinsic to the operators themselves (physical performance, gender, age, expertise, presence of pain, muscle fatigue, etc.). This MV results in changes over time in the postures, trajectories, amplitudes of movement, intra- and inter-segmental coordinations, actuating torques and muscle activations of the operator. For instance, during a sawing activity, Côté et al. observed a decrease in the joint range of motion of the

\footnotetext{
https://doi.org/10.1016/j.apergo.2021.103464

*Corresponding author

@ jonathan.savin@inrs.fr (J. Savin)

ORCID(s): $0000-0002-7479-7898$ (J. Savin); 0000-0002-2125-9172 (C.
} Gaudez); 0000-0002-1875-2097 (V. Padois) elbow of $7^{\circ}$ [10]. More fundamental movements have also been studied. During a repetitive reaching task, Fuller et al. observed a lateral shift of about $12 \mathrm{~mm}$ of the pelvis, as well as an elevation of about $11.7 \mathrm{~mm}$ of the shoulder [11].

Despite the prevalence of MV, workstation designers are usually hardly aware of it. Although small, these variations can be significant in terms of risk factors assessment. Neglecting these drifts in operators' posture, positions and exertions related to MV can lead to erroneous risk assessments, and ultimately inappropriate technical choices in workstation design. In fact, risk factor assessment is a mandatory step in the design process of workstations, as stated in the "EU Machinery Directive" currently in force in Europe [12]. Specifically, work-equipment designers must reduce the risks at the workstation as much as possible, from the earliest stages of workstation design. This approach is called design-integrated risk prevention.

During the early stages in the design of completely new machines and workstations, this risk assessment usually relies on digital simulation of the worker's future activity. Designers may use Digital Human Models (DHM) to check the feasibility of the prescribed task and assess the associated musculoskeletal risk factors thanks to ergonomics indices such as RULA [13], REBA [14], OCRA [15] or EAWS [16]. As an example, let us consider a fictional workstation where an operator is to assemble parts of an engine (cf. figure 1). For safety, the designer adds a casing (carter) with an aperture for safe manual operation. Thanks to a DHM, the designer can compute a nominal trajectory of the operator's hand as well as an ergonomics index for the task. But the operators' activity is highly constrained by the carter, and they may soon experience discomfort, fatigue or pain even if the nominal postures and exertions have been deemed 

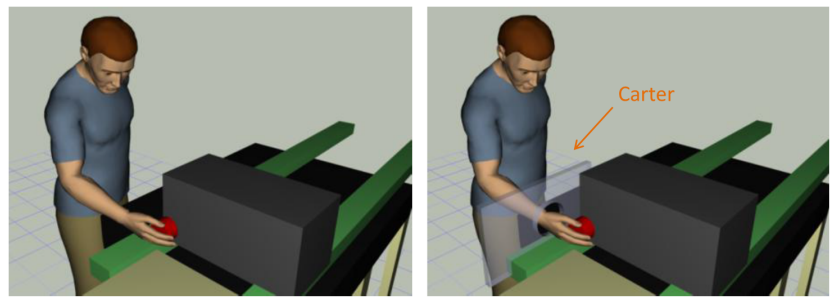

Figure 1: Simulation of a fictional workstation. Current DHM tools consider both configurations as equivalent because they omit MV, potentially leading to the under-estimation of risk factors. Adding MV simulation features in DHM software may help designers improve workstation risk factors' assessment.

"ergonomically correct". Physical risks (collision with the carter) or biomechanical stresses induced by constrained movements may be under-estimated or omitted if $\mathrm{MV}$ is ignored.

Hence, a major challenge in workstation design engineering entails improving DHM tools so that they can also be used to simulate operators' MV and improve the assessment of risk factors at the workstation [9] with simulations which are closer to the real activity of operators.

As an initial preliminary step toward this ambitious goal, the present study aims to characterize the time-evolution of MV throughout a fundamental repetitive task where MV is assumed to be mainly induced by a single identified factor. Our exploratory experiment relies on a fundamental repetitive pointing task with muscle fatigue. Indeed, as muscle fatigue relies on force-repetition interactions which are a possible risk factor for Musculo-Skeletal Disorders (MSD) [17] it may therefore be a concern for workstation designers. Although the task is a very fundamental one, it leads to dynamic movements which can be found at most workstations (picking and placing assembly parts, reaching a control switch button, etc.).

Such a fundamental activity with muscle fatigue has already been described in the literature, for instance by Côté et al. [11, 18-22]. These papers deal with "binary" comparisons of the subjects' postures and movements (before or after fatigue, male or female, with or without pain, with or without additional mass attached to the waist, etc.). The same activity has also been studied by Fuller et al. (2011) who focused on the time evolution of postures and movements, but on a discrete perspective (only parts of the pointing trajectories for the first 10 seconds of each minute were analyzed).

In this study, we focus on a cycle-by-cycle analysis of $\mathrm{MV}$, more precisely on the continuous time evolution of joint angles until exhaustion. Indeed, joint angles are key parameters for ergonomics indices usually used by workstation designers to assess MSD risks. study relies on wellestablished mathematic tools: firstly, a Principal Component Analysis (PCA) is used to filter recorded signals and build dimensionless indices of joint coordination (cf. section 2.4.3); then a non-supervised Hierarchical Ascending Classification (HAC) is applied to the afore-mentioned PCA indices

\begin{tabular}{|l|c|}
\hline Feature & Mean \pm standard deviation \\
\hline Age & $25.8 \pm 3.1$ years \\
\hline Height & $1.79 \pm 0.06 \mathrm{~m}$ \\
\hline Mass & $78.6 \pm 7.5 \mathrm{~kg}$ \\
\hline Body Mass Index $(\mathrm{BMI})$ & $24.6 \pm 2.5 \mathrm{~kg} / \mathrm{m}^{2}$ \\
\hline
\end{tabular}

Table 1

Main anthropometric features for the 13 subjects.

in order to automatically identify successive coordination patterns (cf. section 2.4.5). Finally, the RULA ergonomics index is computed for the first and last patterns of MV identified. This approach is intended to highlight the potential influence of MV on occupational risk assessment and provide information about MV evolution in order to investigate the adaptations in posture and movement identified by Fuller et al. [23]. This approach would also increase our knowledge about human behavior which may later be modelled and implemented into workstation design tools such as DHM to simulate operators' MV from the early stages of workstation design.

\section{Material and methods}

\subsection{Participants}

13 subjects volunteered to participate in the experiment. Exclusion criteria were defined to ensure the consistency of the data recorded and their interpretation: the subjects were all male, right-handed, with "ordinary" physical performance (subjects were not competitive sportsmen in disciplines that strongly involve the shoulders such as tennis, swimming, etc.) and no history of musculoskeletal pathology of the upper limbs. Table 1 presents the main anthropometric features of the 13 subjects.

Experimental data were recorded for the 13 subjects, but some could not be analyzed due to instrumentation issues. For some subjects and signals, data were missing or unusable. The number of subjects or signals considered is specified hereafter, depending on the analysis carried out.

\subsection{Experimental protocol}

This protocol is based on the observation of a repetitive pointing task with fatigue similar to the one described by Côté et al. [11]. The subjects stood without moving their feet. They were asked to touch two targets placed in front of them alternately. The distal target (DST) was a vertical disk (diameter $10 \mathrm{~mm}$ ) placed at a distance equivalent to $100 \%$ of the participants upper-limb length, the proximal target (PRX) a vertical cylinder (height $100 \mathrm{~mm}$, diameter $16 \mathrm{~mm}$ ) placed at $30 \%$ of that distance. Both targets were placed at shoulder height. The rate of a single movement forwards and backwards was fixed at $2 \mathrm{~s}$ by a metronome. The onset of fatigue was brought on by the instruction given to the subjects to maintain the upper limb at shoulder height, materialized by an elliptical obstacle located close to the proximal target which prevented participants lowering their limbs (cf. figure 2). 


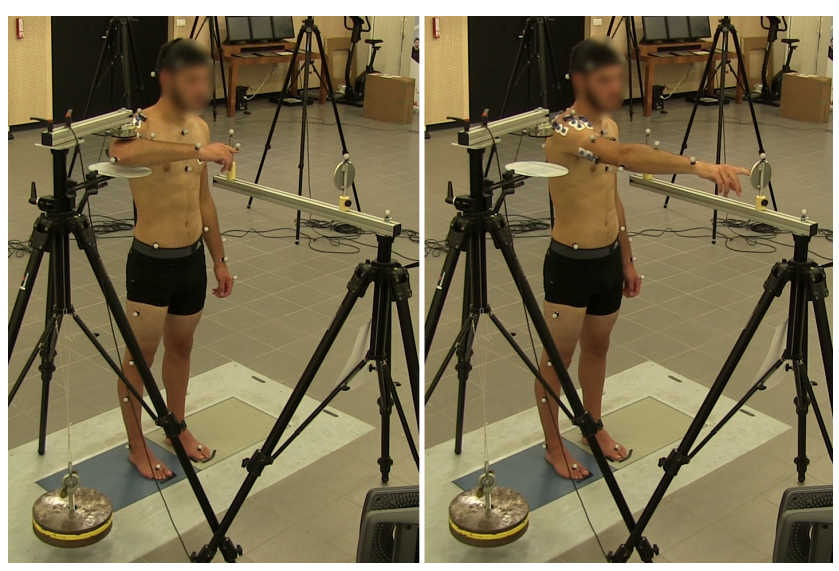

Figure 2: Experimental set-up: repetitive pointing task with fatigue. Subjects touch a vertical cylinder (proximal target PRX), then reach a disk (distal target DST) and go back to PRX. An elliptical obstacle forces the elbow to remain at shoulder height when the subject is close to PRX.

The study was approved by the local ethics committee and conformed to the standards set by the World Medical Association - Declaration of Helsinki "Ethical Principles for Medical Research Involving Human Subjects" [24].

\subsubsection{Experimental conditions}

Three experimental conditions were considered:

Nominal (NOM) The objective of this condition was to characterize the chronological evolution of MV. The subjects executed the task continuously, until one of the stopping criteria was reached (cf. section 2.2.2).

Calibration $(\boldsymbol{C A L})$ This condition was aimed at characterizing the decrease in strength production capacity associated with the onset of muscle fatigue. In this modality, the subject temporarily interrupted the pointing movement during the last $4 \mathrm{~s}$ of each minute to perform a measurement of maximal voluntary exertion (MVE). The abduction force of the right shoulder was measured by a sensor located above the elbow as the subject touched the proximal target (cf. figure 2). This condition was derived from the protocol described in [25] and other works which include brief interruptions of the main task to quantify the onset of fatigue [26]. The $C A L$ condition was continued until one of the stop criteria was met (cf. section 2.2.2).

Control (CTR) The purpose of this last condition was to test whether intermittent measurements of voluntary maximal exertion induced significant fatigue. In this condition, the subjects were at rest for 56 seconds, with the elbow resting on the elliptical obstacle. Then they exerted an MVE for 4 seconds before returning to the resting position. This rest/MVE cycle was repeated for a duration equal to that observed in the $C A L$ condition.
The subjects started randomly with either the NOM or $C A L$ condition, the $C T R$ condition was always performed last. A rest period of 1 hour was observed between each condition to achieve a full recovery.

\subsubsection{Stop criteria}

In the $N O M$ and $C A L$ conditions, the pointing task was performed until the first of the following events occurred:

- the perceived exertion, expressed using the Borg $C R_{10}$ scale [27], reached a score of 8 or higher. This criterion is denoted "RPE" (rate of perceived exertion) hereafter;

- the subject failed to maintain the altitude set point and touched the obstacle placed under their elbow. The experimenter reminded the subject of this altitude set point and encouraged them to carry on. The exercise was stopped on the third contact. This criterion is denoted "Altitude" hereafter;

- the subject gave up or asked to. This criterion is denoted "Abort" hereafter.

"Completion time" $t_{c}$ is the total duration of the pointing activity up to the point that any one of these events occurred.

\subsection{Data acquisition}

Before the experiment, several measurements were carried out on each subject: height, mass, length of the outstretched arm as well as leg length, shoulder height, knee and ankle length and elbow circumference in order to set up the kinematic model of the subject. During the experiment, the following data were collected:

Motion capture (MOCAP): 39 markers were placed on the subject's body according to the Vicon "Plug-inGait" marker set, except for the marker RFIN which was placed at the extremity of the pointing finger instead of at the middle knuckle on the right hand (cf. figure 3). Their cartesian positions were recorded at $100 \mathrm{~Hz}$ using 19 VICON cameras (T10, T10S and Vero 2.2) controlled by a Nexus 2.5 station. Once the MOCAP markers were set up, a static posture recording was made in a reference position (subject standing with both arms horizontal, extended forward) for $5 \mathrm{~s}$.

Muscle activity: surface electromyographic (sEMG) activity was recorded (wireless Zero Wire system, Cometa). The muscles considered were deltoideus pars anterior $\left(D E L_{A}\right)$, pars medialis $\left(D E L_{M}\right)$ and pars posterior $\left(D E L_{P}\right)$, biceps brachii caput longum $(B I C)$, triceps brachii caput longum (TRI) and trapezius pars descendens $\left(T R A_{D}\right)$. The EMG electrodes were positioned in line with the recommendations of the SENIAM project [28]. The acquisition frequency was $1 \mathrm{kHz}$. A 4-second-long maximal voluntary contraction was recorded for the 6 muscles studied before the pointing task for the purpose of normalization. 
Video recording: this was synchronized with the motion and EMG data, and was carried out to facilitate an $a$ posteriori interpretation of the activity (identification of missed targets, parasitic movements, etc.).

MVE force recording: shoulder abduction MVE was recorded by a force transducer (Schunk model FTS-DELTA 660-60 together with its conditioner). This data was synchronized with the motion capture. Only the vertical force $F_{Z}$ was recorded.

Rating of Perceived Exertion: a subjective rate of perceived exertion (RPE) at the shoulder was requested orally from the subject at the end of each minute (just before the MVE for the $C A L$ condition). Numerical values and descriptive labels of the Borg $C R_{10}$ scale were displayed below the DST target throughout the experiment.

\subsection{Data processing \\ 2.4.1. EMG data}

Two descriptors of the EMG activity were calculated for each muscle under consideration:

- the amplitude $\mathcal{A}$ of the EMG envelope, calculated by rectification of the EMG signal and bidirectional Butterworth low-pass filtering of the $4^{\text {th }}$ order with cut-off at $6 \mathrm{~Hz}$ which is equivalent to computing its Root Mean Square (RMS) [29];

- the mean frequency $\mathcal{F}$, calculated from the EMG signal filtered between 20 and $400 \mathrm{~Hz}$.

These descriptors were chosen because they are commonly used to confirm the onset of muscle fatigue through the Joint Analysis of the EMG Amplitude and Spectrum (JASA) criterion [30]. The mean frequency was computed by means of Python packages (scipy.signal and numpy.fft). Instantaneous values of these descriptors were aggregated during pointing cycles $(\mathrm{PRX} \rightarrow \mathrm{DST} \rightarrow \mathrm{PRX}$ trajectory, cf. figure 3 ) of about $2 s$.

\subsubsection{Kinematic MV quantification}

First, raw MOCAP data were formatted using Motion Analysis Cortex software (version 3.16) for both static posture and the NOM-condition pointing activity recordings: marker occlusions and permutations were corrected before data filtering (low-pass $4^{\text {th }}$ order Butterworth with cut-off at $20 \mathrm{~Hz}$ ). Additional 'virtual' markers were also added (pelvis center, joint centers, cf. figure 3). The subjects' geometry and marker positions on their limbs were then computed from the static recording using the OpenSim software scaling tool (version 3.2) [31]. Finally, the OpenSim ik tool was used to compute the inverse kinematics of the pointing activity for the whole body. The DOFs of the upper body used for the subsequent processes and analysis are listed in table 2.

\subsubsection{Cycle-by-cycle PCA of joint angles}

Principal Component Analysis (PCA) has been used in several other works to identify movement coordinations

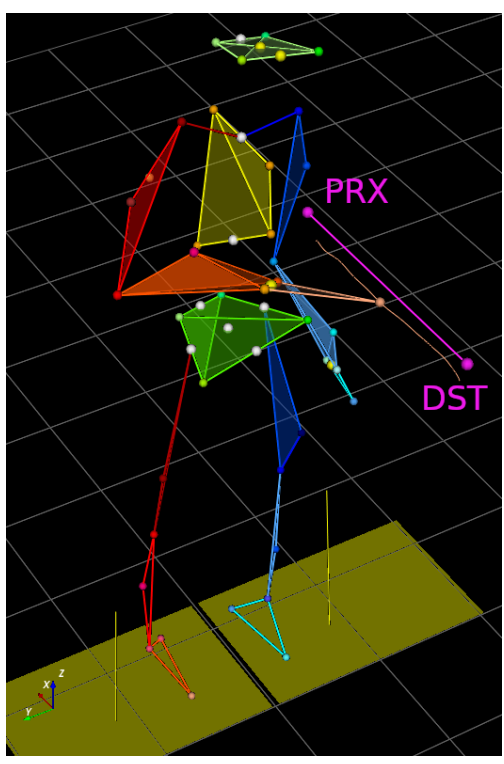

Figure 3: MOCAP markers placed according to the Plug-in Gait convention and additional virtual markers (yellow or grey) used for inverse kinematics. One pointing cycle consists in starting from the proximal target PRX, then touching the distal target DST and finally returning to PRX (purple). For interpretation of the references to color in this figure legend, the reader is referred to the Web version of this article.

\begin{tabular}{|c|c|c|}
\hline Link & DOF (Axis) & Label \\
\hline \multirow{6}{*}{$\begin{array}{l}\text { Lower } \\
\text { Trunk }\end{array}$} & Flexion (Z) & LwTrk Flx \\
\hline & Lateral flexion (X) & LwTrk_Lat \\
\hline & Rotation $(\mathrm{Y})$ & LwTrk Rot \\
\hline & AP translation $(\mathrm{X})$ & - \\
\hline & Lateral translation $(\mathrm{Z})$ & - \\
\hline & Vertical translation ( $\mathrm{Y}$ ) & - \\
\hline \multirow{3}{*}{$\begin{array}{l}\text { Upper } \\
\text { Trunk }\end{array}$} & Flexion (Z) & UpTrk_Flx \\
\hline & Lateral flexion (X) & UpTrk_Lat \\
\hline & Rotation (Y) & UpTrk_Rot \\
\hline \multirow{2}{*}{ Clavicle } & Elevation $(\mathrm{X})$ & RightClav_Elv \\
\hline & Protraction $(\mathrm{Y})$ & RightClav_Prt \\
\hline \multirow{3}{*}{ Shoulder } & Flexion (Z) & RightArm_Flx \\
\hline & Abduction $(X)$ & RightArm_Abd \\
\hline & Rotation $(\mathrm{Y})$ & RightArm_Rot \\
\hline \multirow{2}{*}{ Elbow } & Flexion (Z) & RightForeArm_Flx \\
\hline & Pronation (X) & RightForeArm_Prn \\
\hline \multirow{2}{*}{ Wrist } & Flexion (Z) & RightHand_Flx \\
\hline & Abduction (X) & RightHand_Abd \\
\hline
\end{tabular}

Table 2

Upper body joints and translation DOFs used for inverse kinematics. All 15 joint DOFs were further processed by PCA to identify joint coordinations.

[32, 33]. The aim of PCA is to transform $N$ interrelated signals $s_{i \in[1, N]}$ into $N$ new decorrelated variables $\zeta_{i \in[1, N]}$ called "modes". Modes are computed by linear combinations of the initial signals weighted by coefficients denoted $\alpha_{i}^{j}$ (cf. equation 1). For a complete presentation of PCA and the 
computation of modes $\zeta_{i}$ and weights $\alpha_{i}^{j}$, see [32].

$$
\zeta_{j \in[1, N]}=\sum_{i=1}^{N} \alpha_{i}^{j} s_{j}
$$

In the specific context of movement analysis, thanks to the weights $\alpha_{j}^{i}$ and modes $\zeta_{i}$, one can identify signals in phase or antiphase, as well as those that contribute little or significantly to the movement (cf. figure 11 in Appendix C). However, as Kukke stated, PCA "does not specify how movement is coordinated from a neurophysiological point of view, but rather how different DOFs are coordinated with each other" [33].

In order to analyze the time evolution of movement coordinations, pointing cycles were segmented as follows: each cycle starts and ends at the contact with the proximal target PRX (PRX $\rightarrow$ DST $\rightarrow$ PRX trajectory, cf. figure 3$)$. For each cycle of each subject, a PCA was performed on all joint angles of interest, with a total of $N=15$ analyzed joint DOFs (cf. table 2). PCA was not performed directly on the joint angles $q_{i \in[1, N]}$. Instead, those signals were processed according to the approach described by Kukke et al. [33]. First, a range normalization was performed so that joint angles were converted to values in the interval $[0,1]$ over the whole experiment, with $t_{0}$ and $t_{f}$ being the start and the end of the pointing task (cf. equation 2).

$$
\begin{aligned}
\tilde{q}_{i \in[1, N]}\left(t \in\left[t_{0}, t_{f}\right]\right) & =\frac{q_{i}(t)-q_{i}^{\min }}{q_{i}^{\max }-q_{i}^{\min }} \\
q_{i}^{\min } & =\min _{t \in\left[t_{0}, t_{f}\right]} q_{i}(t) \\
q_{i}^{\max } & =\max _{t \in\left[t_{0}, t_{f}\right]} q_{i}(t)
\end{aligned}
$$

Then, these normalized signals $\tilde{q}_{i}$ were resampled according to time on a cycle-per-cycle basis. For each pointing cycle $k$, let $t_{P R X}^{k}$ be the beginning of the $k^{\text {th }}$ cycle, $t_{D S T}^{k}$ the end of the forward movement and $t_{P R X}^{k+1}$ the beginning of the next cycle. Let $\hat{t}_{i \in[0,100]}$ be the resampling instants so that $\hat{t}_{i \in[0,50]}$ are 51 evenly spaced instants corresponding to the movement PRX $\rightarrow \mathrm{DST}$, and $\hat{t}_{i \in[50,100]}$ are 50 evenly spaced instants corresponding to the reverse movement DST $\rightarrow$ PRX. We now consider the range-normalized time-resampled signals $\hat{q}_{i}^{k}(\hat{t})$ deduced by linear interpolation from $\tilde{q}_{i}(t)$ with $t \in\left[t_{P R X}^{k}, t_{P R X}^{k+1}[\right.$. Figure 4 shows signals for all joint angles, one pointing cycle and one subject. Figure 5 shows the corresponding first 3 modes of the PCA and figure 11 shows PCA weights for the first mode only for the same pointing cycle and subject as in figure 4.

An additional advantage of PCA is that modes $\zeta_{i}$ can be ordered according to the part of the initial information they contain so that the study can be restricted to a limited number of modes, thereby reducing the dimensionality of the analysis. For all the pointing cycles and all subjects, the first mode $\zeta_{1}$ of PCA corresponded approximately to a bellshaped periodic movement (cf. figure 5). It contained most of the information about the pointing movement $(\gtrsim 90 \%)$. Thus, for subsequent analysis, only this mode was studied.

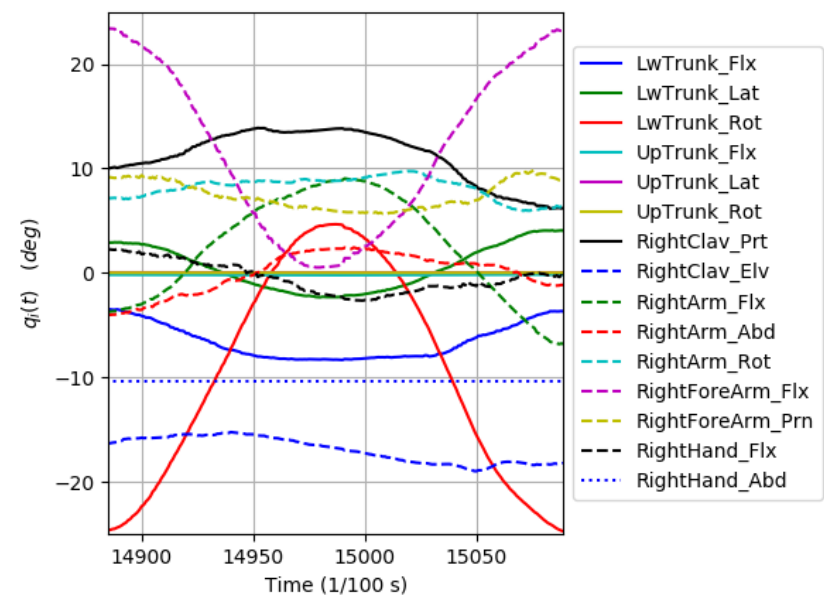

Figure 4: Raw joint angles values $q_{i}(t)$ for one cycle and one subject.

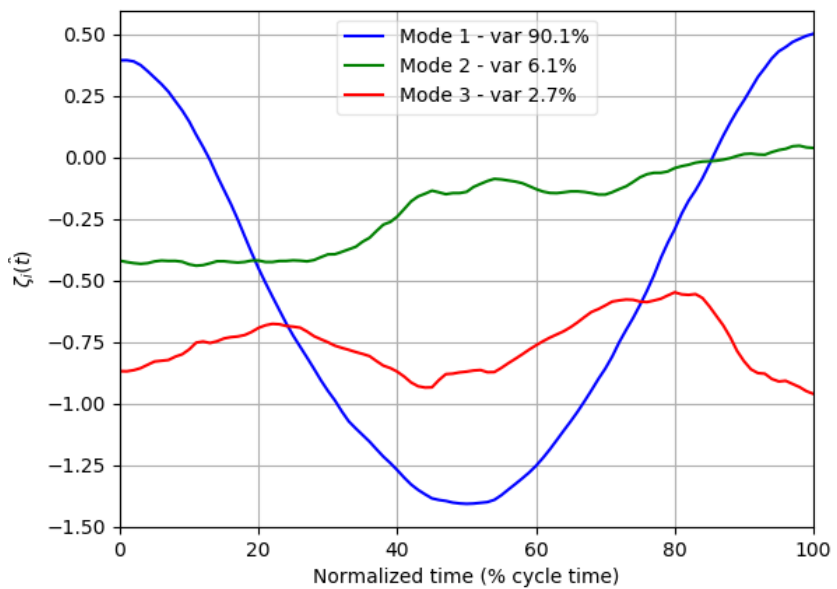

Figure 5: PCA modes $\zeta_{i \in[1,3]}$ and explained variance for one cycle and one subject. Mode $\zeta_{1}$ comprises about $90 \%$ of total variance of this cycle.

\subsubsection{Intra-individual comparison of PCA weights}

Once PCA has been computed for each of the $N_{c}$ pointing cycles for one subject, we analyzed the time-evolution of MV by means of a cycle-by-cycle comparison within each subject. To this end, we studied the time series of the weights $\alpha_{j}^{1}(k)$ for cycles $k \in[1, p]$ and DOF $j \in[1, N]$. More precisely, we computed the relative difference between the weight $\alpha_{j}^{1}(k)$ of DOF $j$ in the first mode $\zeta_{1}$ at cycle $k$ and a reference weight $\bar{\alpha}_{j}^{1}$ for a fictional movement defined as the mean of cycles 6 to 10 (cf. equation 5), chosen arbitrarily according to the hypothesis that the pointing movement was stabilized in the very first 6 cycles [34] and that fatigue onset was not yet significant. Finally, a normalized variable $\delta_{j}(k)$ was computed relative to the range of the $\alpha_{j}^{1}$ in order not to discriminate between DOFs that contribute little and DOFs that contributed significantly to the mode $\zeta_{1}$ (cf. equation 6).

$$
\bar{\alpha}_{j}^{1}=\frac{1}{5} \sum_{k \in[6,10]} \alpha_{j}^{1}(k)
$$


Evidence of movement variability patterns during a pointing task until exhaustion

$$
\delta_{j}(k)=\frac{\alpha_{j}^{1}(k)-\bar{\alpha}_{j}^{1}}{\max _{k=1}^{N} \alpha_{j}^{1}(k)-\min _{k=1}^{N} \alpha_{j}^{1}(k)}
$$

The time evolution of $\delta_{j}(k)$ can be summarized in "coordination maps" (one for each subject, cf. figure 12 in Appendix C) for an intuitive visual interpretation of MV evolution.

\subsubsection{Intra-individual Hierarchical Ascending Classification of cycles}

In order to identify potential homogeneous behaviors in movement coordination within each subject, we applied a non-supervised classification algorithm, namely Hierarchical Ascending Classification (HAC). HAC aims to iteratively group similar individuals into dissimilar classes based on "intra-class homogeneity" and "inter-class heterogeneity" criteria. It consists of the construction of a "tree" (dendrogram) based on a measure of dissimilarity between individuals [35]. In this study, each cycle $c_{k}$ was represented by its coordinates vector $\boldsymbol{\delta}_{k}=\left(\delta_{j}(k)\right) \in \mathbb{R}^{15}$. HAC distributes the $N_{c}$ cycles of pointing activity into several classes according to an inertia criterion (Ward's criterion) associated with Euclidean distance (cf. figure 6 in section 3.4). Computation relied on the linkage function of the Python module scipy. cluster. hierarchy with default parameters.

We hypothesized that successive cycles should be similar, i.e, subjects show smooth variations in movement rather than jerky ones. Hence, the number of HAC classes was chosen empirically for each subject, to reduce the number of "outlier" cycles, with cycle $c_{p}$ defined as an outlier if it belongs to a cluster $C_{i}$ which is different from the cluster(s) $C_{j}$ of its preceding and proceeding neighbours $c_{p-1}$ and $c_{p+1}$ (cf. equation 7).

$$
c_{p} \text { is an outlier if }\left\{\begin{array}{l}
c_{p} \in \mathcal{C}_{i} \\
c_{p-1} \in \mathcal{C}_{j} \\
i \neq j
\end{array} \text { and } c_{p+1} \in \mathcal{C}_{j}\right.
$$

\section{Results}

\subsection{Comparison between NOM, CAL and CTR conditions}

We first compared the three experimental NOM, CTR and $C A L$ conditions. More precisely, the NOM and $C A L$ conditions were compared with respect to the completion time and RPE, then the $C A L$ and $C T R$ conditions were compared with respect to the MVE.

\subsubsection{Completion time}

Table 3 presents the completion times for the two conditions and the 13 available subjects. The most frequent stop criterion was the perceived exertion threshold (for 8 of the 13 subjects in the NOM condition, for 11 of the 13 subjects in the $C A L$ condition).

In the NOM condition, the average completion time was $369 \pm 138 s$ (mean \pm standard deviation). In the $C A L$ condition, it was $360 \pm 135 \mathrm{~s}$. Since the distribution of the

\begin{tabular}{|c|c|c|c|c|}
\hline Sujet & \multicolumn{2}{|c|}{$N O M$ condition } & \multicolumn{2}{c|}{$C A L$ condition } \\
\hline & $t_{c}(\mathrm{~s})$ & Criterion & $t_{c}(\mathrm{~s})$ & Criterion \\
\hline 1 & 180 & RPE & 240 & RPE \\
\hline 2 & 420 & RPE & 300 & RPE \\
\hline 3 & 240 & RPE & 300 & RPE \\
\hline 4 & 180 & RPE & 240 & RPE \\
\hline 5 & 420 & RPE & 360 & RPE \\
\hline 6 & 420 & RPE & 240 & RPE \\
\hline 7 & 360 & RPE & 509 & RPE \\
\hline 8 & 360 & RPE & 320 & Abort \\
\hline 9 & 480 & Altitude & 420 & RPE \\
\hline 10 & 711 & Altitude & 733 & RPE \\
\hline 11 & 366 & Altitude & 360 & Altitude \\
\hline 12 & 370 & Altitude & 360 & RPE \\
\hline 13 & 296 & Abort & 300 & RPE \\
\hline \multicolumn{5}{|c}{} \\
\hline
\end{tabular}

Table 3

Completion time $t_{c}$ for the 13 available subjects. The stop criteria are defined in section 2.2.2.

\begin{tabular}{|c|c|c|}
\hline Subject & $\begin{array}{c}\text { CAL condition } \\
\rho(\mathrm{p})\end{array}$ & $\begin{array}{c}\text { CTR condition } \\
\rho(\mathrm{p})\end{array}$ \\
\hline 4 & $-0.40(0.60)$ & $0.46(0.43)$ \\
\hline 5 & $-0.94(0.00) \star$ & $0.30(0.52)$ \\
\hline 6 & $-0.60(0.40)$ & $-0.40(0.60)$ \\
\hline 7 & $-0.81(0.01) \star$ & $0.39(0.34)$ \\
\hline 8 & $-1.00(0.00) \star$ & $-0.15(0.80)$ \\
\hline 9 & $-0.89(0.01) \star$ & $0.43(0.34)$ \\
\hline 10 & $-0.71(0.01) \star$ & $0.11(0.73)$ \\
\hline 11 & $-0.60(0.28)$ & $-0.09(0.87)$ \\
\hline 12 & $-0.89(0.02) \star$ & $-0.54(0.27)$ \\
\hline 13 & $-0.90(0.04) \star$ & $-0.20(0.74)$ \\
\hline
\end{tabular}

Table 4

Spearman's rank correlations between time and MVE for 10 available subjects. $(\star)$ highlights a significant correlation at a $95 \%$ confidence level.

completion times in the $C A L$ condition was not comparable to a normal distribution, the Wilcoxon non-parametric test was applied. It revealed no significant difference between the two conditions at a level of confidence of $95 \%(p=0.5523)$.

\subsection{2. $R P E$}

The Shapiro-Wilk test confirmed the hypothesis of the normality of RPE under both NOM and CAL conditions. Hence, tests of equality of means and variances have been applied and revealed no significant difference between the two conditions at the 95\% confidence level. Figure 8 in Appendix A illustrates the evolution of perceived exertions in NOM and $C A L$ conditions for all the subjects.

\subsection{3. $M V E$}

The MVE of shoulder abduction was recorded at the end of each minute for both the CAL and CTR conditions. Since the MVE was not normally distributed, Spearman's ranks correlation test was applied to identify any correlation between time and force production. Table 4 shows these results for the MVE available for 10 subjects. 
In the $C A L$ condition for 7 out of the 10 subjects, there was a significant correlation between time and MVE. This correlation was very strong (average value $\tilde{\rho}^{C A L}=-0.88$ ) with the associated $t$-test which was statistically significant at a 95\% confidence level. For the other 3 subjects, the rank correlation remained negative (from -0.60 to -0.40 ) yet the associated $t$-test was not statistically significant at a $95 \%$ confidence level. Nevertheless, these observations support the hypothesis of a reduction in production capacity over time.

In the $C T R$ condition, the average correlation was centered on zero $\left(\tilde{\rho}^{C T R}=0.03, \sigma=0.36\right)$, indicating no correlation between time and MVE. Thus, intermittent MVE exercises appeared to generate no significant reduction in force production capacity.

Figure 9 in Appendix A illustrates MVE time evolution for one subject in both $C A L$ and $C T R$ conditions.

\subsubsection{Consequence for the further analysis}

Since intermittent MVE exercises seemed to have no influence by themselves on force production and there is no statistically significant difference between the NOM and $C A L$ conditions in completion time or in RPE, we focused further analysis on the NOM condition only.

\subsection{Evidences of muscle fatigue based on EMG data}

EMG signals provided evidence of muscle fatigue. A first level of analysis of the occurrence of muscle fatigue consisted of comparing EMG data from the beginning and the end of the experiments, as done in the literature [11, 1821].

On average for the 12 available subjects, the EMG amplitude $\mathcal{A}$ increased significantly during the experiment, while the EMG mean frequency $\mathcal{F}$ decreased significantly between the beginning and the end of the repetitive pointing task (cf. table 5). According to the JASA approach [30], $\mathcal{A}$ and $\mathcal{F}$ indicate muscle fatigue, which is also brought to light by the increase in RPE and decrease in MVE (cf. sections 3.1.2 and 3.1.3).

As there is no consensus regarding a descriptor of muscle fatigue state, a basic statistical analysis has been carried out to qualitatively identify a potential correlation between EMG signals and time. Assuming that muscle fatigue increases over time, we applied the Spearman's correlation test on JASA criteria $\mathcal{A}$ and $\mathcal{F}$ to reveal their potential monotonic evolution with time. This statistic does not rely on a linear dependence of the signal with time, rather it highlights monotonic trends. This analysis revealed a statistically significant correlation between the EMG amplitude $\mathcal{A}$ and time for 70 of the 72 tested signals as well as between the EMG mean frequency $\mathcal{F}$ and time for 65 out of 72 tested signals (cf. tables 13 and 14 in Appendix B).

A synthesis of these correlations is given in table 6: for all subjects considered, the amplitude $\mathcal{A}$ of EMG for each muscle was positively correlated with time $\left(\tilde{\rho}_{\mathcal{A}} \in\right.$

\begin{tabular}{|c|c|c|}
\hline Muscle & $\begin{array}{l}\text { Average amplitude } \\
\text { (mean } \pm \mathrm{SD}) \\
\mathcal{A}(\%)\end{array}$ & $\begin{array}{l}\text { Mean Frequency } \\
(\text { mean } \pm \mathrm{SD}) \\
\mathcal{F}(\mathrm{Hz})\end{array}$ \\
\hline$D E L_{A}$ & $\begin{array}{l}t_{0}: 100.5 \pm 4.5 \\
t_{c}: 134.9 \pm 22.6 \\
\text { Test T: } p=0.0000 \star\end{array}$ & $\begin{array}{l}t_{0}: 124.3 \pm 8.6 \\
t_{c}: 109.0 \pm 7.8 \\
\text { Test } T: p=0.0002 \star\end{array}$ \\
\hline$D E L_{M}$ & $\begin{array}{l}t_{0}: 98.4 \pm 4.2 \\
t_{c}: 144.4 \pm 18.6 \\
\text { Test } T: p=0.0000 \star\end{array}$ & $\begin{array}{l}t_{0}: 124.3 \pm 9.5 \\
t_{c}: 108.6 \pm 5.7 \\
\text { Test T: } p=0.0001 \star\end{array}$ \\
\hline$D E L_{P}$ & $\begin{array}{l}t_{0}: 98.5 \pm 5.1 \\
t_{c}: 160.3 \pm 34.9 \\
\text { Test U: } p=0.0000 \star\end{array}$ & $\begin{array}{l}t_{0}: 118.5 \pm 14.5 \\
t_{c}: 109.7 \pm 10.1 \\
\text { Test T: } p=0.0960(\mathrm{NS})\end{array}$ \\
\hline$B I C$ & $\begin{array}{l}t_{0}: 100.6 \pm 4.9 \\
t_{c}: 175.2 \pm 56.1 \\
\text { Test U: } p=0.0000 \star\end{array}$ & $\begin{array}{l}t_{0}: 122.5 \pm 11.6 \\
t_{c}: 107.2 \pm 10.3 \\
\text { Test T: } p=0.0025 \star\end{array}$ \\
\hline$T R I$ & $\begin{array}{l}t_{0}: 99.9 \pm 4.1 \\
t_{c}: 150.3 \pm 40.4 \\
\text { Test } T: p=0.0003 \star\end{array}$ & $\begin{array}{l}t_{0}: 141.2 \pm 11.8 \\
t_{c}: 124.2 \pm 15.3 \\
\text { Test T: } p=0.0059 \star\end{array}$ \\
\hline$T R A_{D}$ & $\begin{array}{l}t_{0}: 100.8 \pm 4.7 \\
t_{c}: 150.1 \pm 29.9 \\
\text { Test U: } p=0.0000 \star\end{array}$ & $\begin{array}{l}t_{0}: 108.7 \pm 12.8 \\
t_{c}: 109.1 \pm 13.2 \\
\text { Test } T: p=0.9429 \text { (NS) }\end{array}$ \\
\hline
\end{tabular}

Table 5

Evolution of EMG amplitude (expressed in \% of its value for the first cycle) and mean frequency (in $\mathrm{Hz}$ ) for the first cycle $\left(t_{0}\right)$ and the last cycle $\left(t_{c}\right)$ for the 12 available subjects and the 6 muscles recorded. $(\star)$ highlights a significant correlation at a $95 \%$ confidence level according to Student's $T$ test or Mann-Whitney's $U$ test, applied according to the normality of the distributions considered, while (NS) stands for a not significant difference.

\begin{tabular}{|c|c|c|}
\hline Muscle & $\begin{array}{c}\text { Average correlation } \\
\text { between time and } \\
\text { EMG amplitude } \mathcal{A} \\
(\text { mean } \pm \mathrm{SD})\end{array}$ & $\begin{array}{c}\text { Average correlation } \\
\text { between time and } \\
\text { EMG mean freq. } \mathcal{F} \\
\text { (mean } \pm \mathrm{SD})\end{array}$ \\
\hline$D E L_{A}$ & $0.58 \pm 0.28$ & $-0.64 \pm 0.19$ \\
\hline$D E L_{M}$ & $0.66 \pm 0.18$ & $-0.72 \pm 0.19$ \\
\hline$D E L_{P}$ & $0.74 \pm 0.16$ & $-0.55 \pm 0.40$ \\
\hline$B I C$ & $0.80 \pm 0.14$ & $-0.68 \pm 0.24$ \\
\hline$T R I$ & $0.66 \pm 0.25$ & $-0.75 \pm 0.16$ \\
\hline$T R A_{D}$ & $0.53 \pm 0.29$ & $-0.02 \pm 0.35$ \\
\hline
\end{tabular}

Table 6

Average Spearman's correlations between EMG amplitude $\mathcal{A}$ (respectively mean frequency $\mathcal{F}$ ) and time for each muscle and 12 subjects (mean \pm standard deviation SD).

$[0.53,0.80])$ and the mean frequency $\mathcal{F}$ was negatively correlated with time $\left(\tilde{\rho}_{F} \in[-0.75,-0.55]\right)$ except for the Trapezius pars descendens. Figure 10 in Appendix A illustrates such trends for one muscle and one subject. Adding this to monotonic tendencies in MVE and RPE observed for all subjects (cf. figures 8 and 9), we hypothesize a monotonic onset of fatigue throughout the repetitive task.

\subsection{Position and posture adaptations}

Statistically significant adaptations in subjects' position and posture have been observed. For instance, table 7 shows a shift in pelvis position and shoulder altitude between the 
Evidence of movement variability patterns during a pointing task until exhaustion

\begin{tabular}{|c|c|c|c|}
\hline Position & Average shift $(\mathrm{cm})$ & Test & p-value \\
\hline$V R O O T_{x}$ & $-1,3$ & $<0$ & 0.0090 \\
\hline$R S H O_{z}$ & 1,8 & $>0$ & 0.0001 \\
\hline
\end{tabular}

Table 7

Shift of markers for the first cycle $\left(t_{0}\right)$ and the last cycle $\left(t_{c}\right)$ : average value for all subjects. VROOT denotes the anteroposterior translation of the pelvis and $\mathrm{RSHO}_{z}$ the altitude of the right shoulder.

\begin{tabular}{|l|c|c|c|}
\hline DOF & Avrg shift $\left(^{\circ}\right)$ & Test & p-value \\
\hline Trunk lateral flexion & $-3,4$ & $<0$ & 0.0005 \\
\hline Shoulder flexion & -15.3 & $<0$ & 0.0000 \\
\hline Shoulder int. rotation & -13.2 & $<0$ & 0.0005 \\
\hline Forearm flexion & 2.8 & $>0$ & 0.0261 \\
\hline
\end{tabular}

Table 8

Shift in joint angles between the beginning and the end of the repetitive pointing activity (average value for all subjects). p-values of unilateral Student tests $(>0$ or $<0)$ are provided.

beginning and the end of the pointing task. Similarly, table 8 highlights various changes in posture (joint angles). In the literature, such changes in position and posture are assumed to be induced by muscle fatigue $[11,18-21]$.

\subsection{Identification of coordination patterns}

This section focuses on the time-evolution of kinematics variations based on a cycle-by-cycle analysis expressed through joint coordinations identified by PCA throughout the experiment. PCA and HAC processes described in sections 2.4.3 and 2.4.5 were applied to the reconstructed joint angle data of 9 available subjects.

\subsubsection{HAC and chronology}

$\mathrm{HAC}$ is a non-supervised process, so there is, a priori, no expected correlation between its clustering and time. Theoretically, if consecutive cycles were independent of each other, they could be spread in various classes. However, the HAC classes are almost completely made up of chronologically consecutive cycles. This finding indicates a potential sequence of successive homogeneous "patterns" in movement coordination, as hypothesized (cf. section 2.4.5). For subjects S1 (cf. figure 6) and S8 (cf. figure 13 in Appendix D), the classes seem chronologically juxtaposed. $\mathrm{S} 3$ shows comparable behavior but here one class is included in another one (cf. figure 14 in Appendix D). However, this claim may not be as clear when we look at subject S9 for instance, who show several "jumps" from one class to another (cf. figure 15 in Appendix D).

Depending on the subject considered, 3 to 5 classes were identified. Table 15 in Appendix D summarizes the classification results (number of pointing cycles, classes, supposed outliers).

\subsubsection{Statistical analysis of HAC-based classes \\ 3.4.2.1. Initial phase}

Most subjects present a "whole" first chronological class $\mathcal{C}_{\text {init }}$ (cf. figure 6). On the contrary, the first pointing cycles

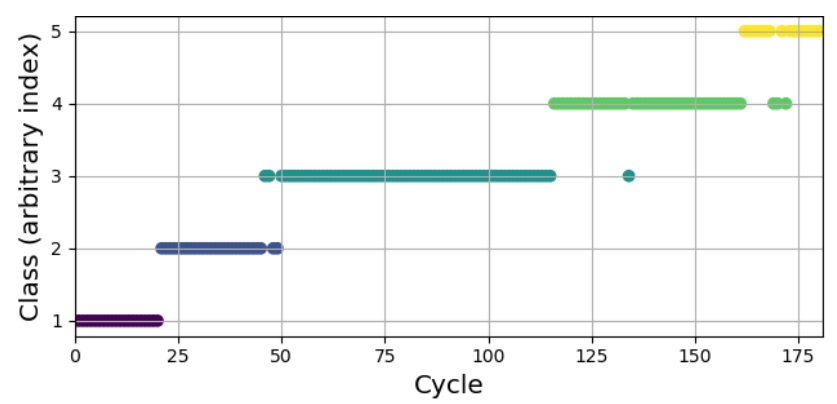

Figure 6: HAC classification of pointing cycles subject S8

\begin{tabular}{|c|c|c|c|}
\hline Subject & $N_{c}$ & Length of $\mathcal{C}_{\text {init }}$ & $\%$ of $N_{c}$ \\
\hline S1 & 96 & 15 & 16 \\
\hline S2 & 214 & 45 & 21 \\
\hline S3 & 119 & 8 & 7 \\
\hline S4 & 90 & 23 & 26 \\
\hline S5 & 210 & 82 & 32 \\
\hline S8 & 189 & 21 & 11 \\
\hline S9 & 247 & 25 & 10 \\
\hline
\end{tabular}

Table 9

Length of the first class in cycles and \% of total number of cycles $N_{c}$.

\begin{tabular}{|c|c|c|c|}
\hline Subject & $N_{c}$ & Length of $\mathcal{C}_{\text {final }}$ & $\%$ of $N_{c}$ \\
\hline S1 & 96 & 5 & 5 \\
\hline S2 & 214 & 20 & 9 \\
\hline S3 & 119 & 12 & 10 \\
\hline S4 & 90 & 18 & 20 \\
\hline S5 & 210 & 125 & 49 \\
\hline S8 & 189 & 19 & 10 \\
\hline S9 & 247 & 47 & 20 \\
\hline
\end{tabular}

Table 10

Length of the last class in cycles and \% of total number of cycles $N_{c}$.

of subjects S6 and S7 belong to a class that is split. For the former, the first class can be described as an "initial coordination pattern". The average length of this class for the 7 subjects considered is about $17 \pm 9 \%$ of the number of pointing cycles (cf. table 9).

\subsubsection{Exhaustion phase}

Similarly, all the subjects except S7 exhibited a monolithic last chronological class $C_{\text {final }}$, with a few possible outlier cycles. This last class could be considered to be the "exhaustion phase". Its average length was about $17 \pm 15 \%$ of the number of pointing cycles for the 7 subjects considered.

\subsubsection{Intermediate phases}

At the inter-individual level, the number of intermediate classes (from 1 to 3 ) depended on the specific subject. This observation is not investigated further in this paper.

At the intra-individual level, statistical analysis has been performed on kinematics data segmented according to the PCA-based HAC classes in order to better describe how 
Evidence of movement variability patterns during a pointing task until exhaustion
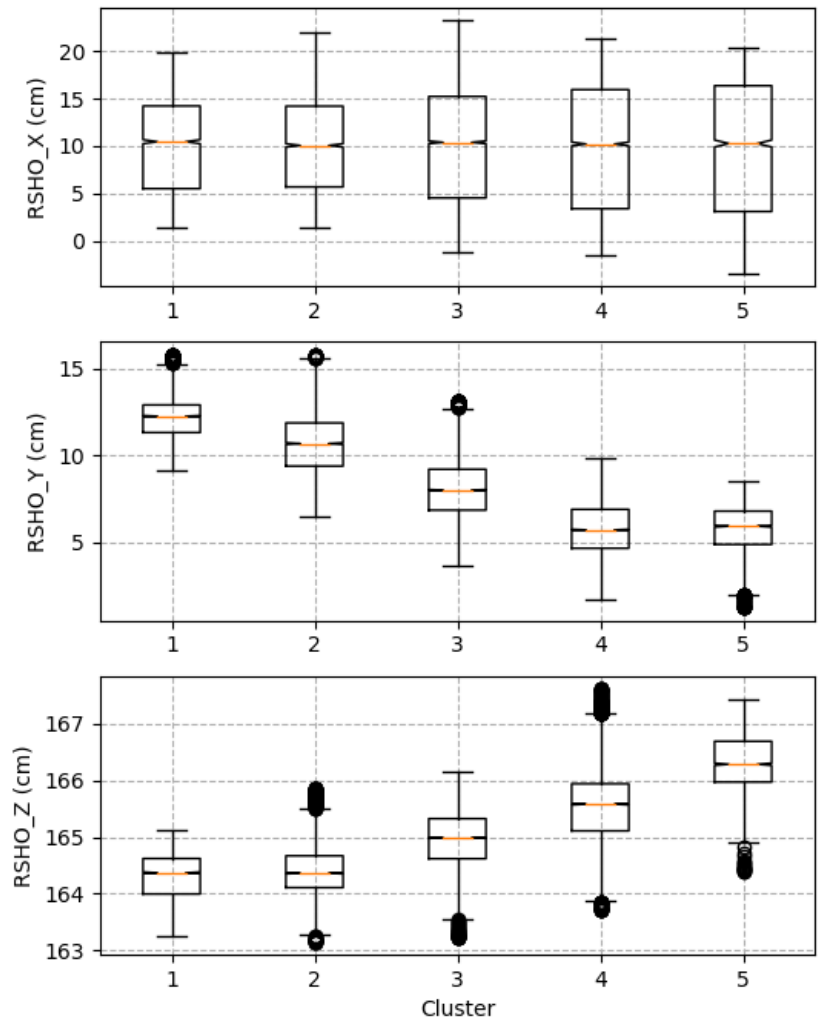

Figure 7: Boxplot of the cartesian position of the shoulder based on HAC segmentation for subject S8. $\mathrm{RSHO}_{X}, R S H O_{Y}$ and $\mathrm{RSHO}_{Z}$ stand for the antero-posterior, medio-lateral and vertical direction, respectively.

these classes differ from one other. For instance, figure 7 shows the time evolution of the cartesian position of the right shoulder for differents subject. It highlights a monotonic drift in shoulder altitude (median in the Z-axis) and position in the medio-lateral direction (median in the Y-axis) as well as a slight increase in range of shoulder displacement along the antero-posterior direction (see the increasing height of the box along the $\mathrm{X}$-axis).

\subsection{Illustrative application to workstation design: evolution of RULA score according to posture and movement adaptations}

Our study focuses on a fundamental repetitive pointing activity in the laboratory, which may seem far removed from occupational conditions. Moreover, it deals with the analysis of joint and segment kinematics variability, which is not a usual concern for working equipment designers and ergonomists. To focus more on their considerations, we applied the widely used ergonomic assessment method RULA to our motion data, as more and more designers are doing with simulated movement data during the first stages of the workstation design process to assess biomechanical risk factors [36-39]. RULA is based on the visual analysis of the most demanding postures adopted by the operator during their activity. Scores are established for different parts of the

\begin{tabular}{|c|c|c|c|}
\hline Subject & Score A8 (LF) & Score A8 (HF) & Trend \\
\hline S1 & $\begin{array}{c}6.4 \pm 0.5 \\
(p=0.0015)\end{array}$ & $\begin{array}{c}5.9 \pm 0.4 \star \\
(p=0.0815)\end{array}$ & $\begin{array}{c}U \searrow \\
(p=0.0061)\end{array}$ \\
\hline S2 & $\begin{array}{c}6.6 \pm 0.3 \\
(p=0.0000)\end{array}$ & $\begin{array}{c}7.1 \pm 0.2 \\
(p=0.0485)\end{array}$ & $\begin{array}{c}U \nearrow \\
(p=0.0000)\end{array}$ \\
\hline S3 & $\begin{array}{c}7.4 \pm 0.3 \\
(p=0.0002)\end{array}$ & $\begin{array}{c}6.7 \pm 0.3 \star \\
(p=0.0943)\end{array}$ & $\begin{array}{c}U \searrow \\
(p=0.0001)\end{array}$ \\
\hline S4 & $\begin{array}{c}7.5 \pm 0.2 \star \\
(p=0.2556)\end{array}$ & $\begin{array}{c}7.1 \pm 0.3 \\
(p=0.0405)\end{array}$ & $\begin{array}{c}U \searrow \\
(p=0.0002)\end{array}$ \\
\hline S5 & $\begin{array}{c}6.3 \pm 0.3 \star \\
(p=0.4114)\end{array}$ & $\begin{array}{c}6.3 \pm 0.3 \star \\
(p=0.2085)\end{array}$ & $\begin{array}{c}T \rightarrow \\
(p=0.3777)\end{array}$ \\
\hline S6 & $\begin{array}{c}5.6 \pm 0.3 \star \\
(p=0.2374)\end{array}$ & $\begin{array}{c}5.9 \pm 0.2 \star \\
(p=0.1641)\end{array}$ & $\begin{array}{c}T \nearrow \\
(p=0.0001)\end{array}$ \\
\hline S7 & $\begin{array}{c}6.9 \pm 0.2 \\
(p=0.0278)\end{array}$ & $\begin{array}{c}6.3 \pm 0.4 \star \\
(p=0.0684)\end{array}$ & $\begin{array}{c}U \searrow \\
(p=0.0000)\end{array}$ \\
\hline S8 & $\begin{array}{c}6.5 \pm 0.3 \star \\
(p=0.1728)\end{array}$ & $\begin{array}{c}6.0 \pm 0.2 \\
(p=0.0150)\end{array}$ & $\begin{array}{c}U \searrow \\
(p=0.0000)\end{array}$ \\
\hline S9 & $\begin{array}{c}6.0 \pm 0.2 \\
(p=0.0166)\end{array}$ & $\begin{array}{c}5.9 \pm 0.3 \\
(p=0.0031)\end{array}$ & $\begin{array}{c}U \searrow \\
(p=0.0168)\end{array}$ \\
\hline
\end{tabular}

Table 11

RULA score A8 (mean \pm SD) with low (LF) or high fatigue (HF). Fatigue is assumed low (resp. high) for the first (resp. last) $20 \%$ of the pointing activity. $(\star)$ denotes a normal distribution according to the Shapiro-Wilk test at 95\% confidence level. Trend is assessed by comparing means through the Student test $(T)$ if both distributions are normal or the Mann-Withney test (U) if at least one sample is not normal.

body [13] from a grid which can be easily implemented into a piece of software.

We automatically computed the RULA scores A8 (overall score for right upper extremity) and B7 (overall score for the trunk-neck-head) based on experimental joint angles, and aggregated them by pointing cycles. Assuming that the first fifth of the activity corresponds to low muscle fatigue (LF) while the last fifth corresponds to high fatigue (HF) (cf. paragraphs 3.4.2.1, 3.4.2.2 and 4.4), tables 11 and 12 show the evolution of the RULA scores A8 and B7 for each subject.

For all the subjects, at least one of the RULA scores changed with the onset of fatigue. For subjects $S 1, S 3$, $S 4$ and $S 9$, the score of the final posture was lower than the initial one; for subjects $S 2, S 5$ and $S 6$, the final score corresponded to a posture that was more demanding than at the beginning; for subjects $S 7$ and $S 8$, the RULA scores corresponded to a transfer of demands from the upper limb to the trunk.

\section{Discussion and perspectives}

\subsection{Comparison with experimental data from similar or comparable activities}

Several papers in the literature have addressed similar pointing activities [11, 18-21]. Our observations are in line with theirs, for instance :

- the completion times $t_{c}$ in the NOM and $C A L$ conditions were $369 \pm 138 s$ and $360 \pm 135 s$ respectively 
Evidence of movement variability patterns during a pointing task until exhaustion

\begin{tabular}{|c|c|c|c|}
\hline Subject & Score B7 (LF) & Score B7 (HF) & Trend \\
\hline S1 & $\begin{array}{c}4.0 \pm 0.3 \star \\
(p=0.1738)\end{array}$ & $\begin{array}{c}4.0 \pm 0.2 \\
(p=0.0010)\end{array}$ & $\begin{array}{c}U \rightarrow \\
(p=0.7042)\end{array}$ \\
\hline S2 & $\begin{array}{c}2.5 \pm 0.3 \\
(p=0.0005)\end{array}$ & $\begin{array}{c}3.4 \pm 0.2 \star \\
(p=0.0811)\end{array}$ & $\begin{array}{c}U \nearrow \\
(p=0.0000)\end{array}$ \\
\hline S3 & $\begin{array}{c}4.6 \pm 0.3 \star \\
(p=0.1058)\end{array}$ & $\begin{array}{c}3.8 \pm 0.4 \star \\
(p=0.3065)\end{array}$ & $\begin{array}{c}\text { T } \\
(p=0.0000)\end{array}$ \\
\hline S4 & $\begin{array}{c}5.2 \pm 0.9 \star \\
(p=0.1005)\end{array}$ & $\begin{array}{c}4.7 \pm 0.6 \\
(p=0.0007)\end{array}$ & $\begin{array}{c}U \rightarrow \\
(p=0.1632)\end{array}$ \\
\hline S5 & $\begin{array}{c}3.1 \pm 0.1 \\
(p=0.0000)\end{array}$ & $\begin{array}{c}3.7 \pm 0.4 \star \\
(p=0.2484)\end{array}$ & $\begin{array}{c}U \nearrow \\
(p=0.0000)\end{array}$ \\
\hline S6 & $\begin{array}{c}6.2 \pm 0.4 \star \\
(p=0.0693)\end{array}$ & $\begin{array}{c}7.7 \pm 0.4 \\
(p=0.0070)\end{array}$ & $\begin{array}{c}U \nearrow \\
(p=0.0000)\end{array}$ \\
\hline S7 & $\begin{array}{c}4.1 \pm 0.3 \\
(p=0.0007)\end{array}$ & $\begin{array}{c}4.4 \pm 0.3 \star \\
(p=0.3370)\end{array}$ & $\begin{array}{c}U \nearrow \\
(p=0.0008)\end{array}$ \\
\hline S8 & $\begin{array}{c}5.2 \pm 0.5 \star \\
(p=0.5116)\end{array}$ & $\begin{array}{c}5.8 \pm 0.7 \\
(p=0.0269)\end{array}$ & $\begin{array}{c}U \nearrow \\
(p=0.0003)\end{array}$ \\
\hline S9 & $\begin{array}{c}3.7 \pm 0.5 \\
(p=0.0000)\end{array}$ & $\begin{array}{c}3.6 \pm 0.3 \\
(p=0.0002)\end{array}$ & $\begin{array}{c}U \rightarrow \\
(p=0.6898)\end{array}$ \\
\hline
\end{tabular}

Table 12

RULA score B7 (mean \pm SD) with low (LF) or high fatigue (HF). Fatigue is assumed low (resp. high) for the first (resp. last) $20 \%$ of the pointing activity. $(\star)$ denotes a normal distribution according to the Shapiro-Wilk test at 95\% confidence level. Trend is assessed by comparing means through the Student test $(T)$ if both distributions are normal or the Mann-Withney test (U) if at least one sample is not normal.

(cf. section 3.1.1). These observations are close to those of Emery and Côté $(360 \pm 120 s)$ [19] and within the confidence interval of those of Fuller et al. $(450 \pm 180 s)[11]$ and Fedorowich et al. $(413 \pm 162 s)$ [20];

- posture and position: we observed an average vertical shift of the shoulder of $18 \mathrm{~mm}$ for all the subjects (cf. section 3.3). This figure is consistent with that reported by Fuller et al., i.e, $11.7 \pm 10.5 \mathrm{~mm}$.

Regarding muscle activity, comparing the beginning and the end of the repetitive reaching task, the average EMG amplitude increased by 50 to $75 \%$ for each subject and each of the muscles considered. This significant increase was greater than that observed by Srinivasan et al. [40] (25$35 \%$ ) but consistent with that observed by Kallenberg et al. [41] (30-58\%). This evolution is statistically significant for the majority of muscles and descriptors, with the exception of the EMG mean frequency $\mathcal{F}$ of Deltoideus pars posterior and Trapezius pars descedans (cf. table 5). The onset of fatigue appeared to be less significant for this last muscle, especially considering the EMG mean frequency $\mathcal{F}$ (cf. table 6). This may be explained by considering that the Trapezius was functionally less involved than others during the pointing activity.

\subsection{Correlations between muscle fatigue and adaptations in posture and movement}

As stated by Fuller et al., the literature suggests that muscle fatigue "leads to within movement alteration at both the

inter-segmental and inter-muscular levels" but "relatively little is known about how muscle fatigue may affect timedependent characteristics of posture and movement control during multijoint tasks" [23]. In fact, many studies rely on the hypothesis that adaptations in postures and movement during a repetitive pointing task are induced by muscle fatigue [11, 18-23].

The analysis carried out in this study highlights the monotonic evolution of fatigue evidences over time during the whole activity for all subjects (decrease in force production capacity and increase of the perceived exertion, increase of EMG amplitude for all muscles recorded, decrease in EMF mean frequency for the majority of muscles recorded, cf. sections 3.1.1 and 3.2). These observations reasonably support the hypothesis of fatigue-induced posture and movement adaptations during the task considered.

\subsection{Time evolution of postures and joint coordination}

The study by Fuller et al. [23] is the only one we know that has addressed changes in temporal coordination alongside muscle fatigue during a repetitive reaching task. Our study now provides new, complementary data to support this:

1. it considers the whole trajectory $(P R X \rightarrow D S T \rightarrow P R X)$ rather than only focusing on the forward part $(\mathrm{PRX} \rightarrow$ DST);

2. it covers the entire pointing activity on a cycle-bycycle basis, rather than only the beginning of each minute;

3. it includes 5 more muscles and deals with the EMG mean frequency $\mathcal{F}$ in addition to its amplitude $\mathcal{A}$

Our study confirms the main observations identified by Fuller: as fatigue develops, it seems to induce adaptations in individual movements, from one cycle to the next. Fuller used a statistical threshold to identify the occurrence of adaptation to fatigue (a deviation greater than $2 \mathrm{SD}$ of the initial value of a parameter)[23]. Applied to the EMG amplitude of the Trapezius, this criterion identified a significant fatigue from $65 \%$ of the completion time. Applied to kinematics parameters (elbow, COM or shoulder position), this criterion identified adaptation in movement and posture as early as $43 \%$ of completion time. Our results suggest that posture and movement occurs even earlier (at about $18 \%$ of completion time according to the average duration of the first class of the HAC) while evidence of fatigue occurs from the very beginning of the task (according to the high Spearman's correlation coefficient of both JASA descriptors). These differences may be explained by the fact that the Trapezius seems to be the least sensitive to fatigue of the muscle considered and that HAC is more flexible than the statistical threshold chosen by Fuller.

\subsection{Limits of this work}

Thirteen subjects participated in this experiment but technical issues somewhat limited the amount of data available for some analysis. This may constitute a limitation in 
the interpretation of experimental data as a fundamental study. However, this study has led to observations which are very consistent with several other works based on the same protocol but with different subjects [11, 18, 19, 23]. Applying PCA and HAC techniques to these existing data with the same protocol may resolve this uncertainty but this is out of the scope of this article.

\subsection{Interpretation of adaptations in posture and movement: issues and opportunities}

One motivation of this study was to make workstation designers more aware of movement variability. Our results confirm that MV exists even in a seemingly basic and constrained task, where designers would not expect it to be significant. They also support the hypothesis that it appears from the very early stages of fatigue onset, inducing adaptations in coordination responses throughout task performance. Moreover, our results also show that current RULA features, already available in design tools such as Virtual Reality (VR) and DHM, may help workstation designers interpret MV data simulated at the early stages of the design process or recorded with the final prototype of the work equipment.

Another motivation of our study was to increase our knowledge of human behavior which may later be modelled. In fact, movement variability is challenging in that betweensubjects and within-subjects effects are superimposed, the former being usually greater than the latter [42]. Nevertheless, the exploratory approach described in this paper has led to the following findings:

- despite the abundancy in the musculoskeletal system, which theoretically allows an infinite number of continuously distributed possible movement trajectories, this experimental pointing activity has highlighted that subjects used a limited set of joint coordination classes, i.e, movement patterns that they preferentially adopted chronologically. This finding concurs with the distinction between movement diversity and movement variability defined by Lémonie [43]: movement diversity refers to a finite set of "attractors" adopted by operators in the continuum of possible trajectories that forms movement variability;

- patterns that make up movement diversity may lead to statistically different postures and trajectories (cf. section 3.5). These changes in kinematics may affect the assessment of occupational risks. For instance, adopting one pattern or another may cause several joint angles to exceed the thresholds of the ergonomics indices or scores considered. Computing those ergonomics indices in relation to at least a few of those patterns may help practitioners interpret MV data qualitatively and improve workstation risk assessments.

- fatigue-induced MV appeared early on in the experiment for all the subjects.
Such findings should be confirmed for activities more representative of professional work situations. Nonetheless, the fact that only a few MV patterns may be encountered may encourage further research, especially considering movement analysis and the simulation of MV. For instance,

- in this study, we used an automatic non-supervised classification tool to detect homogeneous coordination patterns. However, this classification only uses kinematics data. Mixing EMG and kinematics data may confirm or even improve such classification. Innovative statistical tools are being developed that may improve the processing of such heterogeneous signals $[44,45]$;

- these classes may correspond to specific behaviors linked, for instance, to the stabilization of the task's performance (learning the task), to successive adaptations in muscle fatigue and eventually to exhaustion. Beyond the observation of their relative differences, it would be instructive, especially in the case of the onset of muscle fatigue, to investigate how these clusters differ functionally from one other, and why subjects change from one to another. Inverse Optimal Control techniques $[46,47]$ could be applied to each MV pattern to identify the differences between them and the underlying changes in motor strategies (minimization of jerk, torque, energy, discomfort ?) [48, 49];

- digital human models (DHM) are currently used to simulate operators' activity from the early stages of workstation design $[50,51]$. They could be supplemented with muscle fatigue models $[52,53]$ and control laws inspired by the previously mentioned adaptation in motor strategies to simulate predictable MV patterns, as proposed by Gaudez, Gilles and Savin [9]. This would help workstation designers account for the entire future activity, rather than simulating only one nominal posture that will undoubtedly change during the work shift.

\section{Conclusion}

In this study, we investigated a fundamental repetitive pointing activity carried out until exhaustion, focusing on the analysis of the chronological evolution of kinematic MV (joint angles and coordinations) using Principal Component Analysis (PCA) and Hierarchical Ascending Classification (HAC). Our works highlighted that, even for such a basic and constrained activity, muscle fatigue induced MV at both the inter- and intra-individual levels. At the intraindividual level, this MV was manifested, for the majority of the subjects, by successive coordination patterns leading to statistically different postures and trajectories. At the interindividual level, this MV corresponded to the use of 3 to 5 coordination patterns relying on different body joints. The computation of the RULA index showed significant differences in the postures adopted during the experiment 
and helped identify which parts of the body were affected by such adaptations.

These results should be confirmed for activities more representative of occupational tasks. Nevertheless, they should at least raise the awareness of workstation designers and risk prevention practitioners of the need to take MV into account. They should also encourage motor control and motion analysis experts to provide extensive knowledge which could later be modelled and integrated to simulate operators' MV from the early stages of the work equipment design process. This will indeed become a valuable addition, especially considering that the use of complex work equipments such as collaborative robots and exoskeletons is increasing rapidly in factories, which may dramatically reduce operators' ability to use their natural MV.

\section{References}

[1] S. E. Mathiassen, A. Burdorf, A. J. van der Beek, Statistical power and measurement allocation in ergonomic intervention studies assessing upper trapezius emg amplitude: A case study of assembly work, Journal of Electromyography and Kinesiology 12 (2002) 45-57.

[2] P. Madeleine, B. Lundager, M. Voigt, L. Arendt-Nielsen, The effects of neck-shoulder pain development on sensory-motor interactions among female workers in the poultry and fish industries. a prospective study, International archives of occupational and environmental health 76 (2003) 39-49.

[3] P. Madeleine, B. Lundager, M. Voigt, L. Arendt-Nielsen, Standardized low-load repetitive work: evidence of different motor control strategies between experienced workers and a reference group, Applied Ergonomics 34 (2003) 533-542.

[4] S. E. Mathiassen, T. Möller, M. Forsman, Variability in mechanical exposure within and between individuals performing a highly constrained industrial work task, Ergonomics 46 (2003) 800-824.

[5] J. A. Jackson, S. E. Mathiassen, P. G. Dempsey, Methodological variance associated with normalization of occupational upper trapezius emg using sub-maximal reference contractions, Journal of electromyography and kinesiology 19 (2009) 416-427.

[6] M. L. Latash, The bliss (not the problem) of motor abundance (not redundancy), Experimental brain research 217 (2012) 1-5.

[7] D. Srinivasan, S. E. Mathiassen, Motor variability - an important issue in occupational life, Work 41 (2012) 2527-2534.

[8] D. Srinivasan, S. E. Mathiassen, Motor variability in occupational health and performance, Clinical Biomechanics 27 (2012) 979-993.

[9] C. Gaudez, M. Gilles, J. Savin, Intrinsic movement variability at work. How long is the path from motor control to design engineering?, Applied Ergonomics 53, Part A (2016) 71-78.

[10] J. N. Côté, P. A. Mathieu, M. F. Levin, A. G. Feldman, Movement reorganization to compensate for fatigue during sawing, Experimental brain research 146 (2002) 394-398.

[11] J. R. Fuller, K. V. Lomond, J. Fung, J. N. Côté, Posture-movement changes following repetitive motion-induced shoulder muscle fatigue, Journal of Electromyography and Kinesiology 19 (2009) 1043-1052.

[12] M. Directive, Directive 2006/42 of the European Parliament and of the council on machinery, EC of the European Parliament and of the Council of 17 (2006).

[13] L. McAtamney, E. N. Corlett, Rula: a survey method for the investigation of work-related upper limb disorders, Applied ergonomics 24 (1993) 91-99.

[14] S. Hignett, L. McAtamney, Rapid Entire Body Assessment (REBA), Applied Ergonomics 31 (2000) $201-205$.

[15] E. Occhipinti, Ocra: a concise index for the assessment of exposure to repetitive movements of the upper limbs, Ergonomics 41 (1998) 1290-1311.
[16] K. Schaub, G. Caragnano, B. Britzke, R. Bruder, The european assembly worksheet, Theoretical Issues in Ergonomics Science 14 (2013) 616-639.

[17] S. Gallagher, M. C. Schall Jr, Musculoskeletal disorders as a fatigue failure process: evidence, implications and research needs, Ergonomics 60 (2017) 255-269.

[18] K. V. Lomond, J. N. Côté, Differences in posture-movement changes induced by repetitive arm motion in healthy and shoulder-injured individuals, Clinical Biomechanics 26 (2011) 123-129.

[19] K. Emery, J. N. Côté, Repetitive arm motion-induced fatigue affects shoulder but not endpoint position sense, Experimental brain research 216 (2012) 553-564.

[20] L. Fedorowich, K. Emery, B. Gervasi, J. N. Côté, Gender differences in neck/shoulder muscular patterns in response to repetitive motion induced fatigue, Journal of Electromyography and Kinesiology 23 (2013) 1183-1189.

[21] H. Cantú, K. Emery, J. N. Côté, Effects of additional external weight on posture and movement adaptations to fatigue induced by a repetitive pointing task, Human movement science 35 (2014) 1-16.

[22] M. Slopecki, K. Messing, J. N. Côté, Is sex a proxy for mechanical variables during an upper limb repetitive movement task? an investigation of the effects of sex and of anthropometric load on muscle fatigue, Biology of sex Differences 11 (2020) 1-12.

[23] J. R. Fuller, J. Fung, J. N. Côté, Time-dependent adaptations to posture and movement characteristics during the development of repetitive reaching induced fatigue, Experimental brain research 211 (2011) 133-143.

[24] D. O. H. WMA, Ethical principles for medical research involving human subjects, 59th WMA General Assembly, WM Association, Editor (2008).

[25] D. R. Rogers, D. T. MacIsaac, A comparison of emg-based muscle fatigue assessments during dynamic contractions, Journal of Electromyography and Kinesiology 23 (2013) 1004-1011.

[26] R. M. Enoka, J. Duchateau, Muscle fatigue: what, why and how it influences muscle function, The Journal of physiology 586 (2008) $11-23$.

[27] G. A. Borg, Psychophysical bases of perceived exertion., Medicine \& science in sports \& exercise (1982).

[28] H. Hermens, B. Freriks, The state of the art on sensors and sensor placement procedures for surface electromyography: a proposal for sensor placement procedures, Deliverable of the SENIAM Project (1997).

[29] P. Konrad, The abc of emg, A practical introduction to kinesiological electromyography 1 (2005) 30-5.

[30] A. Luttmann, M. Jäger, W. Laurig, Electromyographical indication of muscular fatigue in occupational field studies, International journal of Industrial ergonomics 25 (2000) 645-660.

[31] S. L. Delp, F. C. Anderson, A. S. Arnold, P. Loan, A. Habib, C. T. John, E. Guendelman, D. G. Thelen, Opensim: open-source software to create and analyze dynamic simulations of movement, IEEE transactions on biomedical engineering 54 (2007) 1940-1950.

[32] A. Daffertshofer, C. J. Lamoth, O. G. Meijer, P. J. Beek, Pca in studying coordination and variability: a tutorial, Clinical biomechanics 19 (2004) 415-428.

[33] S. N. Kukke, L. A. Curatalo, A. C. de Campos, M. Hallett, K. E. Alter, D. L. Damiano, Coordination of reach-to-grasp kinematics in individuals with childhood-onset dystonia due to hemiplegic cerebral palsy, IEEE Transactions on Neural Systems and Rehabilitation Engineering 24 (2015) 582-590.

[34] D. H. Gates, J. B. Dingwell, The effects of neuromuscular fatigue on task performance during repetitive goal-directed movements, Experimental Brain Research 187 (2008) 573-585.

[35] D. Müllner, Modern hierarchical, agglomerative clustering algorithms, 2011.

[36] A. Azizi, P. G. Yazdi, M. Hashemipour, Interactive design of storage unit utilizing virtual reality and ergonomic framework for production optimization in manufacturing industry, International Journal on Interactive Design and Manufacturing (IJIDeM) 13 (2019) 373-381. 
[37] V. Havard, B. Jeanne, M. Lacomblez, D. Baudry, Digital twin and virtual reality: a co-simulation environment for design and assessment of industrial workstations, Production \& Manufacturing Research 7 (2019) 472-489.

[38] M. A. Rizzuto, M. W. Sonne, N. Vignais, P. J. Keir, Evaluation of a virtual reality head mounted display as a tool for posture assessment in digital human modelling software, Applied ergonomics 79 (2019) $1-8$.

[39] R. D. Barkokebas, C. Ritter, X. Li, M. Al-Hussein, Application of virtual reality to perform ergonomic risk assessment in industrialized construction: Experiment design, in: Construction Research Congress 2020: Safety, Workforce, and Education, American Society of Civil Engineers Reston, VA, pp. 405-413.

[40] D. Srinivasan, K. E. Sinden, S. E. Mathiassen, J. N. Côté, Gender differences in fatigability and muscle activity responses to a shortcycle repetitive task, European journal of applied physiology 116 (2016) 2357-2365

[41] L. A. Kallenberg, E. Schulte, C. Disselhorst-Klug, H. J. Hermens, Myoelectric manifestations of fatigue at low contraction levels in subjects with and without chronic pain, Journal of electromyography and kinesiology 17 (2007) 264-274.

[42] C. Gaudez, P. Wild, M. A. Gilles, J. Savin, L. Claudon, D. Bailleul, Study of between-subject and within-subject variability of electromyography data and its intrinsic determinants for clip fitting tasks, International Journal of Occupational Safety and Ergonomics (2019) $1-15$.

[43] Y. Lémonie, Des marges de manœuvre à la diversité et à la variabilité motrice dans la prévention des tms, Le travail humain 82 (2019) 6797.

[44] F. Harlé, Détection de ruptures multiples dans des séries temporelles multivariées: application à l'inférence de réseaux de dépendance, Ph.D. thesis, Université Grenoble Alpes, 2016.

[45] A. Leroux, Méthode bayésienne de détection de rupture et/ou de tendance pour des données temporelles, Ph.D. thesis, Université de Montréal, 2016.

[46] K. Mombaur, A. Truong, J.-P. Laumond, From human to humanoid locomotion-an inverse optimal control approach, Autonomous robots 28 (2010) 369-383.

[47] D. Clever, K. Hatz, K. Mombaur, Studying dynamical principles of human locomotion using inverse optimal control, PAMM 14 (2014) 801-802.

[48] B. Berret, E. Chiovetto, F. Nori, T. Pozzo, Evidence for composite cost functions in arm movement planning: an inverse optimal control approach, PLoS Comput Biol 7 (2011) e1002183.

[49] N. Sylla, V. Bonnet, G. Venture, N. Armande, P. Fraisse, Human arm optimal motion analysis in industrial screwing task, in: 5th IEEE RAS/EMBS International Conference on Biomedical Robotics and Biomechatronics, IEEE, pp. 964-969.

[50] G. De Magistris, A. Micaelli, P. Évrard, C. Andriot, J. Savin, C. Gaudez, J. Marsot, Dynamic control of dhm for ergonomic assessments, International Journal of Industrial Ergonomics 43 (2013) 170-180.

[51] P. Maurice, V. Padois, Y. Measson, P. Bidaud, Experimental assessment of the quality of ergonomic indicators for dynamic systems computed using a digital human model, International Journal of Human Factors Modelling and Simulation 5 (2016) 190-209.

[52] E. Rashedi, M. A. Nussbaum, A review of occupationally-relevant models of localised muscle fatigue, International journal of human factors modelling and simulation 5 (2015) 61-80.

[53] E. Rashedi, M. A. Nussbaum, Mathematical models of localized muscle fatigue: sensitivity analysis and assessment of two occupationallyrelevant models, PloS one 10 (2015) e0143872.

\section{A. Complementary information about experimental conditions}

Figures 8, 9 and 10 illustrate time evolution of objective and subjective data described in sections 3.1 and 3.2.
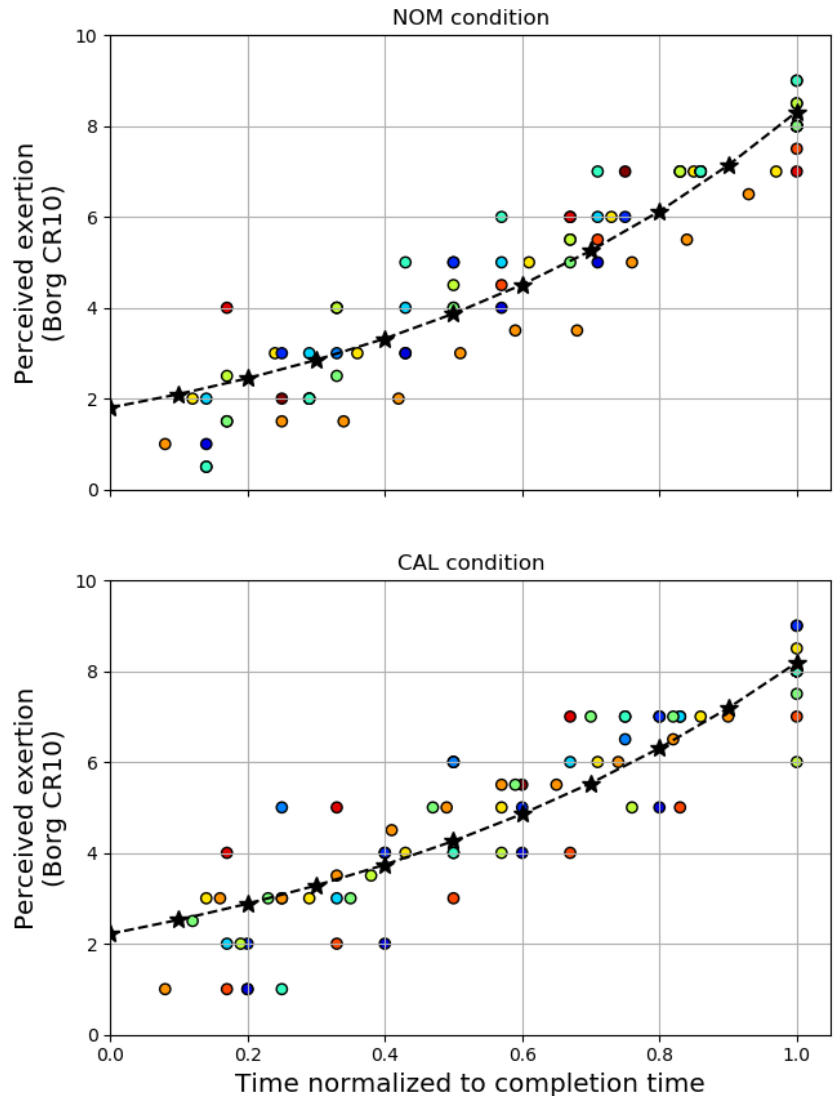

Figure 8: Perceived exertion in NOM and CAL conditions, for the 13 subjects (one color per subject). As an indication, an exponential $(\star)$ regression is plotted.

\section{B. Correlation between muscle fatigue descriptors and time}

Tables 13 and 14 contain the results of the correlation tests described in section 3.2.

\section{Complementary information about PCA}

Figures 11 and 12 illustrate PCA descriptors defined in sections 2.4.3 and 2.4.4.

\section{Complementary information about HAC}

Figures 13, 14 and 15 and table 15 illustrate HAC classes mentioned in section 3.4.1. 

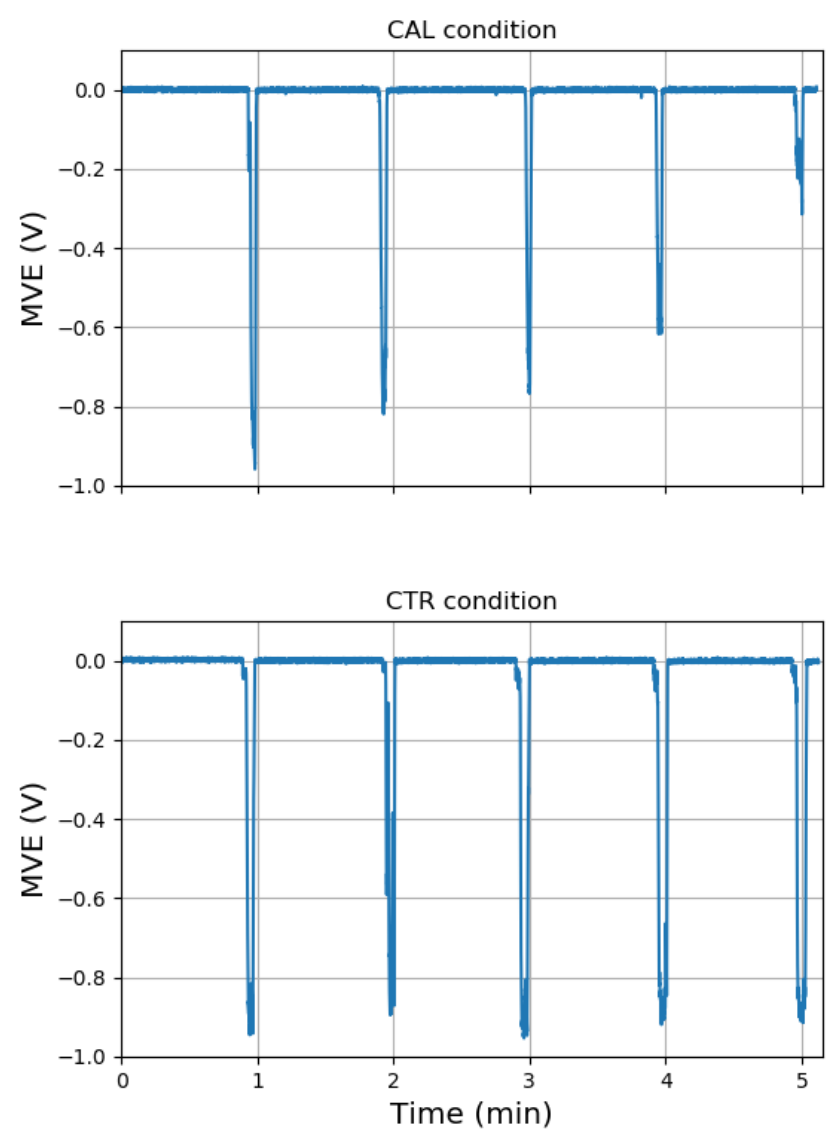

Figure 9: Time evolution of shoulder abduction force production capacity (MVE) in CAL (top) and CTR (bottom) conditions for subject S8.
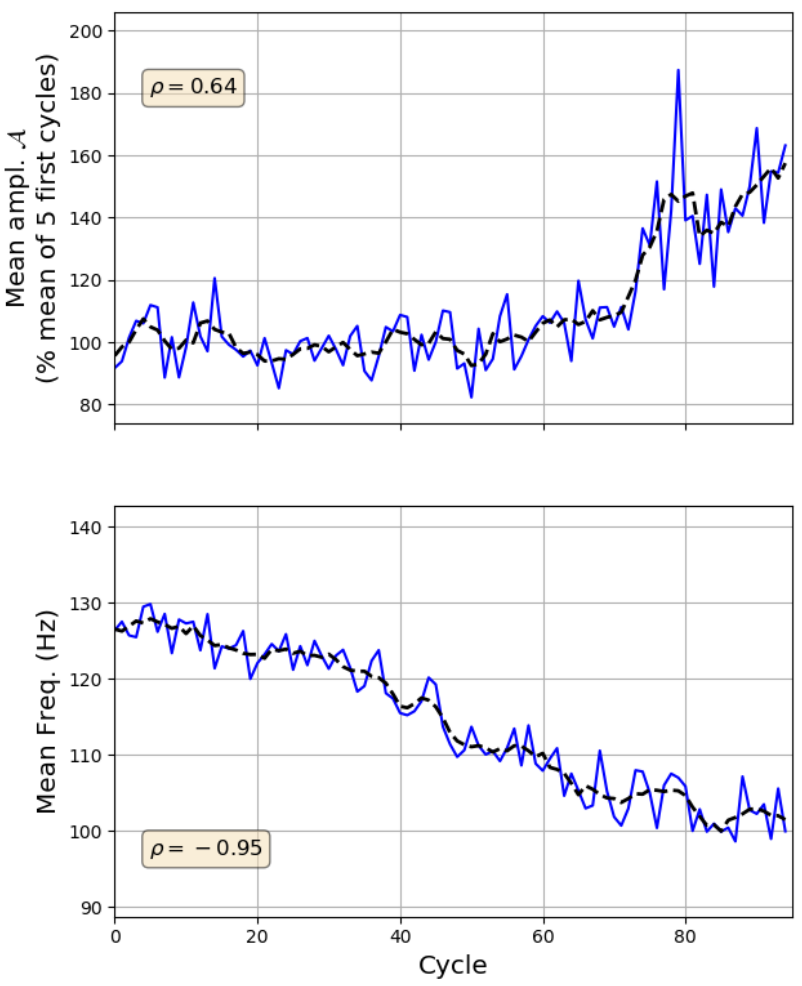

Figure 10: Two descriptors of deltoideus medialis EMG, aggregated over each of the 95 cycles performed by subject S1. Top: EMG envelope $\mathcal{A}$, normalized to the average of this descriptor over the first 5 cycles $(10 \mathrm{~s})$. Bottom: mean frequency $\mathcal{F}$. Solid line: raw data. Dotted line: moving average over 5 cycles $(10 \mathrm{~s})$. A Spearman's correlation coefficient $\rho$ has been computed on each signal to test if a monotonic trend exists.

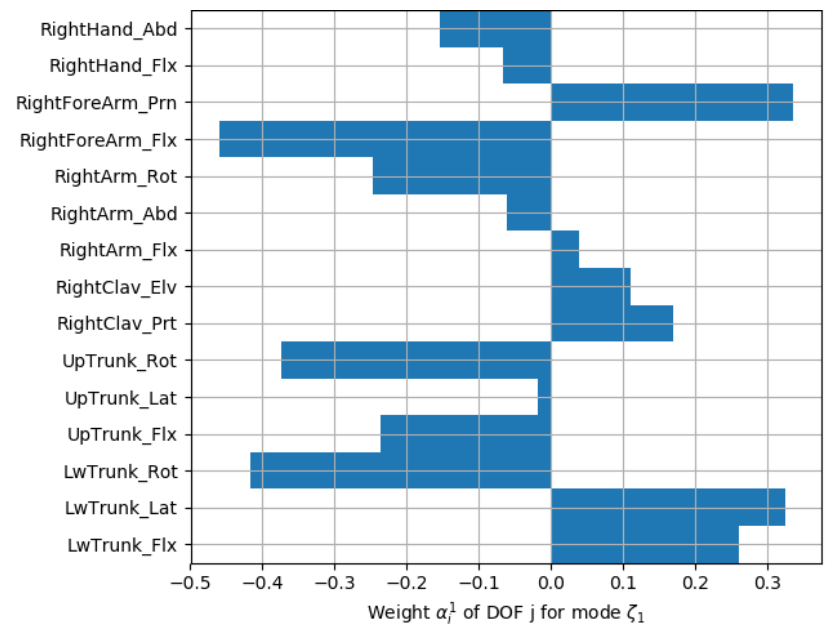

Figure 11: PCA weights $\alpha_{j \in[1, N]}^{1}$ of the first mode for one cycle and one subject. This diagram highlights DOFs in phase (same sign) or antiphase (opposite signs), as well as DOFs that contribute weakly $\left(\left|\alpha_{j}^{1}\right| \approx 0\right)$ or strongly $\left(\left|\alpha_{j}^{1}\right| \gg 0\right)$ to this mode. 


\begin{tabular}{|c|c|c|c|c|}
\hline $\begin{array}{l}\text { Spearman's } \\
\text { correlation } \\
\text { of EMG } \mathcal{A} \\
\text { with time }\end{array}$ & S1 & S2 & S3 & S4 \\
\hline$D E L_{A}$ & $\begin{array}{c}0.73 \\
(0.0000) \\
\end{array}$ & $\begin{array}{c}0.86 \\
(0.0000)\end{array}$ & $\begin{array}{c}0.20 \\
(0.0275)\end{array}$ & $\begin{array}{c}0.53 \\
(0.0000) \\
\end{array}$ \\
\hline$D E L_{M}$ & $\begin{array}{c}0.64 \\
(0.0000)\end{array}$ & $\begin{array}{c}0.90 \\
(0.0000)\end{array}$ & $\begin{array}{c}0.47 \\
(0.0000)\end{array}$ & $\begin{array}{c}0.58 \\
(0.0000)\end{array}$ \\
\hline$D E L_{P}$ & $\begin{array}{c}0.72 \\
(0.0000)\end{array}$ & $\begin{array}{c}0.79 \\
(0.0000)\end{array}$ & $\begin{array}{c}0.91 \\
(0.0000)\end{array}$ & $\begin{array}{c}0.87 \\
(0.0000)\end{array}$ \\
\hline$B I C$ & $\begin{array}{c}0.92 \\
(0.0000)\end{array}$ & $\begin{array}{c}0.96 \\
(0.0000)\end{array}$ & $\begin{array}{c}0.55 \\
(0.0000)\end{array}$ & $\begin{array}{c}0.63 \\
(0.0000)\end{array}$ \\
\hline$T R I$ & $\begin{array}{c}0.78 \\
(0.0000)\end{array}$ & $\begin{array}{c}0.67 \\
(0.0000)\end{array}$ & $\begin{array}{c}-0.03 \dagger \\
\mathbf{( 0 . 7 8 1 7 )}\end{array}$ & $\begin{array}{c}0.70 \\
(0.0000)\end{array}$ \\
\hline \multirow[t]{2}{*}{$T R A_{D}$} & $\begin{array}{c}0.68 \\
(0.0000) \\
\end{array}$ & $\begin{array}{c}0.92 \\
(0.0000)\end{array}$ & $\begin{array}{c}0.76 \\
(0.0000)\end{array}$ & $\begin{array}{c}0.48 \\
(0.0000) \\
\end{array}$ \\
\hline & S5 & S6 & S7 & S8 \\
\hline$D E L_{A}$ & $\begin{array}{c}0.54 \\
(0.0000)\end{array}$ & $\begin{array}{c}0.67 \\
(0.0000)\end{array}$ & $\begin{array}{c}0.73 \\
(0.0275)\end{array}$ & $\begin{array}{c}0.79 \\
(0.0000)\end{array}$ \\
\hline$D E L_{M}$ & $\begin{array}{c}0.90 \\
(0.0000)\end{array}$ & $\begin{array}{c}0.77 \\
(0.0000)\end{array}$ & $\begin{array}{c}0.80 \\
(0.0000)\end{array}$ & $\begin{array}{c}0.78 \\
(0.0000)\end{array}$ \\
\hline$D E L_{P}$ & $\begin{array}{c}0.94 \\
(0.0000)\end{array}$ & $\begin{array}{c}0.60 \\
(0.0000)\end{array}$ & $\begin{array}{c}0.85 \\
(0.0000)\end{array}$ & $\begin{array}{c}0.81 \\
(0.0000)\end{array}$ \\
\hline$B I C$ & $\begin{array}{c}0.83 \\
(0.0000)\end{array}$ & $\begin{array}{c}0.89 \\
(0.0000)\end{array}$ & $\begin{array}{c}0.87 \\
(0.0000)\end{array}$ & $\begin{array}{c}0.82 \\
(0.0000)\end{array}$ \\
\hline$T R I$ & $\begin{array}{c}0.77 \\
(0.0000)\end{array}$ & $\begin{array}{c}0.87 \\
(0.0000)\end{array}$ & $\begin{array}{c}0.49 \\
(0.0000)\end{array}$ & $\begin{array}{c}0.90 \\
(0.0000)\end{array}$ \\
\hline \multirow[t]{2}{*}{$T R A_{D}$} & $\begin{array}{c}0.73 \\
(0.0000) \\
\end{array}$ & $\begin{array}{c}0.52 \\
(0.0000) \\
\end{array}$ & $\begin{array}{c}-0.17 \\
(0.0199) \\
\end{array}$ & $\begin{array}{c}0.53 \\
(0.0000) \\
\end{array}$ \\
\hline & S9 & S10 & S11 & S12 \\
\hline$D E L_{A}$ & $\begin{array}{c}0.79 \\
(0.0000) \\
\end{array}$ & $\begin{array}{c}-0.04 \dagger \\
(\mathbf{0 . 4 3 3 7})\end{array}$ & $\begin{array}{c}0.84 \\
(0.0275)\end{array}$ & $\begin{array}{c}0.35 \\
(0.0000) \\
\end{array}$ \\
\hline$D E L_{M}$ & $\begin{array}{c}0.49 \\
(0.0000)\end{array}$ & $\begin{array}{c}0.64 \\
(0.0000)\end{array}$ & $\begin{array}{c}0.70 \\
(0.0000)\end{array}$ & $\begin{array}{c}0.31 \\
(0.0000)\end{array}$ \\
\hline$D E L_{P}$ & $\begin{array}{c}0.49 \\
(0.0000)\end{array}$ & $\begin{array}{c}0.50 \\
(0.0000)\end{array}$ & $\begin{array}{c}0.78 \\
(0.0000)\end{array}$ & $\begin{array}{c}0.60 \\
(0.0000)\end{array}$ \\
\hline$B I C$ & $\begin{array}{c}0.71 \\
(0.0000)\end{array}$ & $\begin{array}{c}0.64 \\
(0.0000)\end{array}$ & $\begin{array}{c}0.95 \\
(0.0000)\end{array}$ & $\begin{array}{c}0.84 \\
(0.0000)\end{array}$ \\
\hline$T R I$ & $\begin{array}{c}0.74 \\
(0.0000)\end{array}$ & $\begin{array}{c}0.46 \\
(0.0000)\end{array}$ & $\begin{array}{c}0.82 \\
(0.7817)\end{array}$ & $\begin{array}{c}0.75 \\
(0.0000)\end{array}$ \\
\hline$T R A_{D}$ & $\begin{array}{c}0.20 \\
(0.0014)\end{array}$ & $\begin{array}{c}0.42 \\
(0.0000)\end{array}$ & $\begin{array}{c}0.87 \\
(0.0000)\end{array}$ & $\begin{array}{c}0.52 \\
(0.0000)\end{array}$ \\
\hline
\end{tabular}

Table 13

Spearman's correlation results $(\rho, p)$ between EMG amplitude $\mathcal{A}$ (expressed in \% of its value for the first cycle) and time for the 12 available subjects and the 6 muscles recorded. ( $\dagger)$ highlights a non-significant correlation at a $95 \%$ confidence level.

\begin{tabular}{|c|c|c|c|c|}
\hline $\begin{array}{l}\text { Spearman's } \\
\text { correlation } \\
\text { of EMG } \mathcal{F} \\
\text { with time }\end{array}$ & S1 & S2 & S3 & S4 \\
\hline$D E L_{A}$ & $\begin{array}{c}-0.89 \\
(0.0000)\end{array}$ & $\begin{array}{c}-0.96 \\
(0.0000)\end{array}$ & $\begin{array}{c}-0.50 \\
(0.0000)\end{array}$ & $\begin{array}{c}-0.81 \\
(0.0000)\end{array}$ \\
\hline$D E L_{M}$ & $\begin{array}{c}-0.95 \\
(0.0000)\end{array}$ & $\begin{array}{c}-0.69 \\
(0.0000)\end{array}$ & $\begin{array}{c}-0.92 \\
(0.0000)\end{array}$ & $\begin{array}{c}-0.92 \\
(0.0000)\end{array}$ \\
\hline$D E L_{P}$ & $\begin{array}{c}-0.85 \\
(0.0000)\end{array}$ & $\begin{array}{c}-0.70 \\
(0.0000)\end{array}$ & $\begin{array}{c}-0.69 \\
(0.0000)\end{array}$ & $\begin{array}{c}-0.87 \\
(0.0000)\end{array}$ \\
\hline$B I C$ & $\begin{array}{c}-0.78 \\
(0.0000)\end{array}$ & $\begin{array}{c}-0.82 \\
(0.0000)\end{array}$ & $\begin{array}{c}-0.64 \\
(0.0000)\end{array}$ & $\begin{array}{c}-0.82 \\
(0.0000)\end{array}$ \\
\hline$T R I$ & $\begin{array}{c}-0.70 \\
(0.0000)\end{array}$ & $\begin{array}{c}-0.85 \\
(0.0000)\end{array}$ & $\begin{array}{c}-0.85 \\
(0.0000)\end{array}$ & $\begin{array}{c}-0.96 \\
(0.0000)\end{array}$ \\
\hline \multirow[t]{2}{*}{$T R A_{D}$} & $\begin{array}{c}-0.24 \\
(0.0173)\end{array}$ & $\begin{array}{c}-0.43 \\
(0.0000)\end{array}$ & $\begin{array}{c}0.07 \dagger \\
\mathbf{( 0 . 4 2 9 6 )}\end{array}$ & $\begin{array}{c}-0.41 \\
(0.0001)\end{array}$ \\
\hline & S5 & S6 & S7 & S8 \\
\hline$D E L_{A}$ & $\begin{array}{c}-0.57 \\
(0.0000)\end{array}$ & $\begin{array}{c}-0.30 \\
(0.0000)\end{array}$ & $\begin{array}{c}-0.46 \\
(0.0000)\end{array}$ & $\begin{array}{c}-0.64 \\
(0.0000)\end{array}$ \\
\hline$D E L_{M}$ & $\begin{array}{c}-0.48 \\
(0.0000)\end{array}$ & $\begin{array}{c}-0.49 \\
(0.0000)\end{array}$ & $\begin{array}{c}-0.78 \\
(0.0000)\end{array}$ & $\begin{array}{c}-0.84 \\
(0.0000)\end{array}$ \\
\hline$D E L_{P}$ & $\begin{array}{c}-0.80 \\
(0.0000)\end{array}$ & $\begin{array}{c}-0.47 \\
(0.0000)\end{array}$ & $\begin{array}{c}-0.70 \\
(0.0000)\end{array}$ & $\begin{array}{c}-0.92 \\
(0.0000)\end{array}$ \\
\hline$B I C$ & $\begin{array}{c}-0.88 \\
(0.0000)\end{array}$ & $\begin{array}{c}-0.87 \\
(0.0000)\end{array}$ & $\begin{array}{c}-0.07 \dagger \\
\mathbf{( 0 . 3 4 8 8 )}\end{array}$ & $\begin{array}{c}-0.90 \\
(0.0000)\end{array}$ \\
\hline$T R I$ & $\begin{array}{c}-0.81 \\
(0.0000)\end{array}$ & $\begin{array}{c}-0.77 \\
(0.0000)\end{array}$ & $\begin{array}{c}-0.69 \\
(0.0000)\end{array}$ & $\begin{array}{c}-0.60 \\
(0.0000)\end{array}$ \\
\hline \multirow[t]{2}{*}{$T R A_{D}$} & $\begin{array}{c}0.00 \dagger \\
(\mathbf{0 . 9 6 4 4 )}\end{array}$ & $\begin{array}{c}0.01 \dagger \\
(\mathbf{0 . 9 0 7 4})\end{array}$ & $\begin{array}{c}0.12 \dagger \\
(\mathbf{0 . 1 2 3 9})\end{array}$ & $\begin{array}{c}-0.62 \\
(0.0000)\end{array}$ \\
\hline & S9 & $\mathrm{S} 10$ & S11 & S12 \\
\hline$D E L_{A}$ & $\begin{array}{c}-0.64 \\
(0.0000)\end{array}$ & $\begin{array}{c}-0.57 \\
(0.0000)\end{array}$ & $\begin{array}{c}-0.70 \\
(0.0000)\end{array}$ & $\begin{array}{c}-0.68 \\
(0.0000)\end{array}$ \\
\hline$D E L_{M}$ & $\begin{array}{c}-0.44 \\
(0.0000)\end{array}$ & $\begin{array}{c}(0.000) \\
(0.0000)\end{array}$ & $\begin{array}{c}-0.80 \\
(0.0000)\end{array}$ & $\begin{array}{c}-0.76 \\
(0.0000)\end{array}$ \\
\hline$D E L_{P}$ & $\begin{array}{c}-0.25 \\
(0.0000)\end{array}$ & $\begin{array}{c}-0.03 \dagger \\
(\mathbf{0 . 5 7 1 4})\end{array}$ & $\begin{array}{c}-0.70 \\
(0.0000)\end{array}$ & $\begin{array}{c}0.41 \\
(0.0000)\end{array}$ \\
\hline$B I C$ & $\begin{array}{c}-0.54 \\
(0.0000)\end{array}$ & $\begin{array}{c}-0.42 \\
(0.0000)\end{array}$ & $\begin{array}{c}-0.70 \\
(0.0000)\end{array}$ & $\begin{array}{c}-0.74 \\
(0.0000)\end{array}$ \\
\hline$T R I$ & $\begin{array}{c}-0.45 \\
(0.0000)\end{array}$ & $\begin{array}{c}-0.55 \\
(0.0000)\end{array}$ & $\begin{array}{c}-0.94 \\
(0.0000)\end{array}$ & $\begin{array}{c}-0.85 \\
(0.0000)\end{array}$ \\
\hline$T R A_{D}$ & $\begin{array}{c}0.30 \\
(0.0000)\end{array}$ & $\begin{array}{c}0.00 \dagger \\
(\mathbf{0 . 9 3 3 5 )}\end{array}$ & $\begin{array}{c}0.57 \\
(0.0000)\end{array}$ & $\begin{array}{c}0.36 \\
(0.0000)\end{array}$ \\
\hline
\end{tabular}

Table 14

Spearman's correlation results $(\rho, p)$ between EMG mean frequency $\mathcal{F}$ and time for the 12 available subjects and the 6 muscles recorded. ( $\dagger$ ) highlights a non-significant correlation at a $95 \%$ confidence level. 


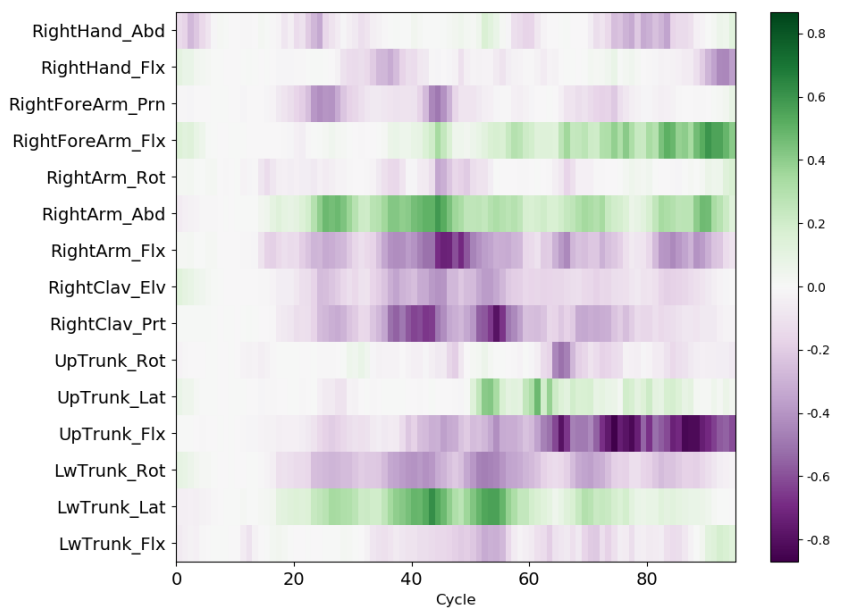

Figure 12: Color maps illustrating the time evolution of the joint coordinations. The color's intensity of each tile characterizes the variation $\delta_{j}$ in the weight of each DOF in the calculation of mode $\zeta_{1}$ of PCA for cycle $k$. A pale colour indicates a joint movement very similar to the reference movement. A deeper color (green or purple) shows an increasing weight (in absolute value). A change in color (from purple to green for instance, such as for the hand abduction in the middle of the experiment), shows an inversion in the coordination pattern.

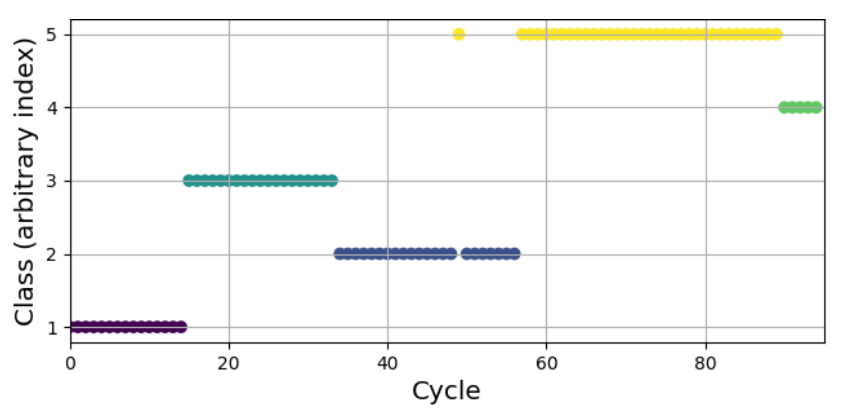

Figure 13: HAC classification of pointing cycles subject S1

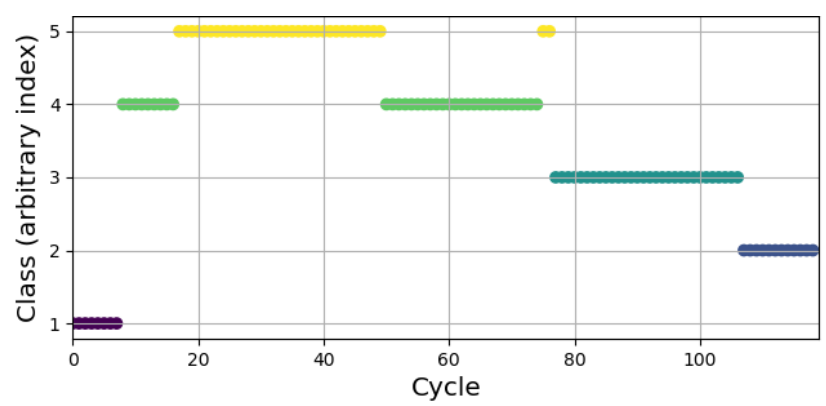

Figure 14: HAC classification of pointing cycles subject S3

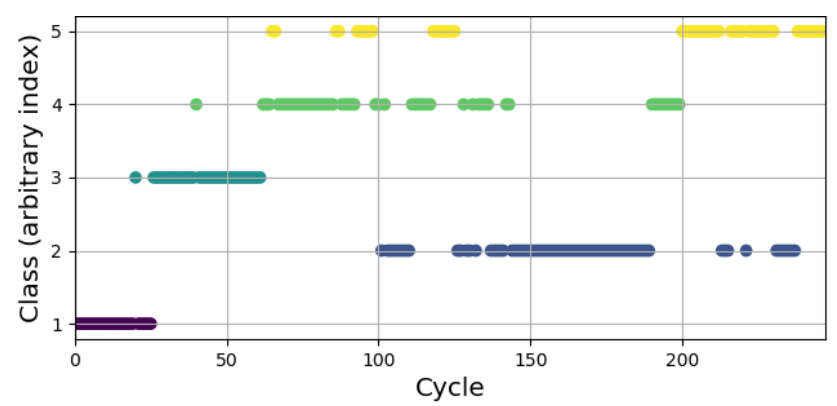

Figure 15: HAC classification of pointing cycles subject $S 9$

\begin{tabular}{|c|c|c|l|}
\hline Subject & Cycles & Classes & Outliers \\
\hline S1 & 96 & 5 & $1(\# 50)$ \\
\hline S2 & 214 & 3 & $\begin{array}{l}12(\# 28,29,40,88,101,102, \\
125,126,149-151,193)\end{array}$ \\
\hline S3 & 119 & 5 & $2(\# 76,77)$ \\
\hline S4 & 90 & 4 & $8(\# 1,2,9,10,43,79,89,90)$ \\
\hline S5 & 210 & 3 & $5(\# 31,69-71,91)$ \\
\hline S6 & 213 & 4 & 0 \\
\hline S7 & 180 & 4 & $\begin{array}{l}12(\# 85,95,121,122,128, \\
136,146,147,152-154,166)\end{array}$ \\
\hline S8 & 183 & 5 & $\begin{array}{l}6 \\
(\# 47,48,135,170,171,173)\end{array}$ \\
\hline S9 & 247 & 3 & $\begin{array}{l}7(\# 19,99,127,129,141,142, \\
220)\end{array}$ \\
\hline
\end{tabular}

Table 15

Summary of HAC classification. For each subject, the number of classes is empirically chosen to reduce the number of outlier pointing cycles. Depending on subjects, from 3 to 5 classes have been built, characterized by 0 to 12 outlier cycles. 